\title{
Environmental regulation and manufacturing carbon emissions in China: a new perspective on local government competition
}

\author{
Chanyuan $\mathrm{Liu}^{1} \cdot$ Long Xin ${ }^{1,2}$. Jinye $\mathrm{Li}^{1}$
}

Received: 3 August 2021 / Accepted: 7 December 2021 / Published online: 21 January 2022

(c) The Author(s), under exclusive licence to Springer-Verlag GmbH Germany, part of Springer Nature 2021

\begin{abstract}
Environmental regulation is a crucial way to achieve manufacturing green transformation. However, few studies have explored the spatial spillover effects and regional boundaries of environmental regulation on manufacturing carbon emissions from the perspective of local government competition. Based on the manufacturing panel data of 30 provinces in China from 2007 to 2019, this paper uses the spatial Durbin model to examine the impact mechanisms, spatial spillover effects, regional boundaries and industry heterogeneity of environmental regulation, and local government competition on manufacturing carbon emissions. The results show that (1) environmental regulation suppresses local manufacturing carbon emissions, local government competition increases local manufacturing carbon emissions, but the interaction indicates that local governments tend to top-to-top competition under the constraints of environmental regulation. (2) The spatial spillover effect of environmental regulation has regional boundaries. The regional boundary with a positive spillover effect is $600 \mathrm{~km}$, and the regional boundary with a negative spillover effect is $1600 \mathrm{~km}$. (3) Environmental regulation and local government competition have spatial heterogeneity in the carbon reduction effects of seven-type manufacturing industries. These findings suggest concrete evidence for developing policies for further encouraging green development in manufacturing.
\end{abstract}

Keywords Environmental regulation $\cdot$ Local government competition $\cdot$ Manufacturing carbon emissions $\cdot$ Regional boundary

\section{Introduction}

As global climate governance enters the full implementation stage of the Paris Agreement, there is an urgent need for countries worldwide to implement and enhance capacity to reduce carbon emissions and strive to achieve the goal of global temperature control (Li et al. 2019; Fernando and Hor 2017; Chontanawat 2020). China overtook the United States to become the world's largest carbon dioxide emitter in 2007 (Dong et al. 2013). In 2020, carbon emissions

Responsible Editor: Baojing Gu

Long Xin

xl_0325168@163.com

$\triangle$ Jinye Li

lijinyexd@sina.com

1 School of Economics and Management, Xinjiang University, Urumqi 830046, China

2 Centre for Innovation Management Research, Xinjiang University, Urumqi 830046, China reached 9.899 billion tons, accounting for $30.7 \%$ of global carbon emissions. In the face of increasingly severe carbon emissions, China has actively made commitments and efforts to set medium- and long-term carbon emission reduction targets. Specifically, at the 75th session of the United Nations General Assembly in September 2020, China first made a commitment of "carbon peak by 2030 and carbon neutrality by 2060," which opened a new journey in China's climate governance work. Subsequently, the Central Economic Work Conference in March 2021 incorporated "carbon peak and carbon neutrality" into the overall layout of ecological civilization construction, promoting carbon emission reduction from a strategic goal to a national strategic plan, which raises the carbon emission reduction work to an unprecedented level, and manufacturing carbon emissions (MCE) are therefore highly concerned.

Since the reform and opening up, China's manufacturing industry has been growing rapidly (Lin and Chen 2020). From 2007 to 2019, the added value of the manufacturing industry increased from 8.75 trillion yuan in 2007 to 26.92 trillion yuan in 2019 , with an annual growth rate of 
$9.82 \%$ and a global share of $28.1 \%$. Among the more than 500 major industrial products globally, China ranks first in the world in terms of output of more than 220 industrial products, making outstanding achievements in manufacturing development. However, as a highly energy-intensive industry, the rapid development in the manufacturing sector is accompanied by a large amount of energy consumption and carbon emissions (Lin and Chen 2018; Lee and Choi 2021; Abokyi et al. 2021; Haseeb et al. 2020). The average annual growth rate of manufacturing energy consumption is $4.14 \%$, and the average annual growth rate of MCE reaches $3.01 \%$ from 2007 to 2019 (NBS 2020), which not only poses a great challenge and pressure on overall carbon emission reduction, but also causes a series of problems such as the decline in environmental quality, damage to public health, and unsustainable economic development. Therefore, energy conservation and emission reduction in manufacturing is imminent (Li et al. 2019; Chontanawat 2020).

Encouragingly, environmental regulation (ER) is regarded as an effective means for the government to improve environmental quality (Guo and Chen 2018; Hashmi and Alam 2019; Ulucak et al. 2020) and is favored by governments and valued by regulators in environmental governance. In response to the growing problem of environmental pollution caused by MCE, the Chinese government has proposed specific emission reduction targets and taken positive environmental regulation measures to control carbon emissions through enhanced ecological supervision (Chen et al. 2018). For example, "Made in China 2025" explicitly sets the target of reducing carbon emissions per unit of added value by $40 \%$ from 2015 to 2025. At the same time, the Chinese government has formulated a series of laws, regulations, and plans for environmental governance, such as the Environmental Protection Tax Law, the Industrial Green Development Plan (2016-2020), and the Guidance on Strengthening Prevention and Control of the Ecological Environment Source of High Energy Consumption and High Emission Construction Projects (2021) (Li et al. 2019; Zhu et al. 2018). Specifically, in the manufacturing sector, the Chinese government has increased its regulation of the high energy-consuming sectors of the manufacturing industry, particularly in the backward steel enterprises, chemical industry, power generation, building materials (especially cement), coal, mining, metallurgy, and other high-emission sectors. Strengthening regulation of projects with high energy consumption and high emissions helps achieve energy saving and carbon reduction (Li and Lin 2017a; Lee and Choi 2021; Garg et al 2020). And undeniably, environmental regulations are increasingly becoming a critical force for local governments to control manufacturing carbon emissions.

However, due to the decentralized governance of the Chinese government, local governments have the discretion to formulate environmental laws and regulations (Jin et al. 2005; Zheng 2007), resulting in different competing approaches to environmental governance by local governments (Driessen et al. 2012; Van Laerhoven and Barnes 2014). On the one hand, local governments compete for the bottom by relaxing environmental regulations at the expense of the environment in pursuit of economic growth. On the other hand, local governments compete for the top by strengthening environmental regulations and balancing the economy and the environment to enhance competitiveness and promote quality economic development. It is surprising that in manufacturing carbon emission governance, the impact of changes in environmental regulation strategies induced by local government competition (LGC) has been ignored. In addition, due to the enormous differences in production in the manufacturing sub-sectors, there is significant sectoral heterogeneity in carbon emissions, which poses significant challenges to manufacturing low-carbon development (Sun et al. 2019; Shahnazi and Shabani 2021). More importantly, with the construction of the new dualcycle development pattern in China, consumer demand is increasing, and the transformation and upgrading and transfer in the manufacturing are accelerating, which leads to an intensification of inter-regional air pollution and even affects the air quality of the surrounding areas through the spillover effect (Chen et al. 2016; Lu et al. 2019; Anselin 1989; Samreen and Majeed 2020; Shahnazi and Shabani 2021). However, so far, few studies have discussed the externality and industry heterogeneity of environmental regulation on MCE from the perspective of local government competition.

To fill the above academic gaps, based on the manufacturing panel data of 30 provinces in China from 2007 to 2019, this study analyzes the influence mechanism, spillover effect, regional boundary, and industry heterogeneity of environmental regulation on MCE from the perspective of local government competition. It attempts to answer the following questions: (1) Do environmental regulation and MCE have spatiotemporal differentiation characteristic? (2) Are there spatial spillover effects of environmental regulation and local government competition on MCE? What's the impact? Does local government competition present "bottom-to-bottom competition" or "top-to-top competition"? (3) Further, is there spatial heterogeneity in the impact of environmental regulation on MCE? Solving the above problems may help policymakers to formulate targeted environmental regulations according to the manufacturing heterogeneity industry and also help to promote "energy saving and carbon reduction" in manufacturing, thereby providing useful references for achieving the goal of "carbon peak and carbon neutrality" and dealing with global climate governance.

Compared with previous studies, the possible marginal contribution in this paper is as follows: (1) Different from previous studies that only explore the impact of environmental regulation on regional carbon emissions, this study 
puts environmental regulation, local government competition, and MCE into a unified framework, deeply analyzes the effect of environmental regulation on MCE, and explores the role of local government competition, which expands the existing research and provides a new research perspective for manufacturing carbon emission reduction. (2) Based on different spatial weight matrices, the spatial Durbin model (SPDM) is employed to analyze the impact mechanism, spatial spillover effect, and regional boundary of ER and LGC on MCE and further explore the spatial heterogeneity of the manufacturing industry segment, which provides new ideas for reducing MCE. (3) Based on the micro-scale industry, this paper sinks to the manufacturing level to explore the impact of ER and LGC on MCE in an attempt to provide an empirical reference for formulating targeted and discrepant industry environmental policies.

The rest of the paper is as follows: the "Literature review and theoretical hypotheses" section reviews the existing literature and proposes theoretical hypotheses; the "Methodology and data" section describes methodology and data; the "Empirical results" section analyzes empirical results; the "Conclusions and discussions" section presents conclusions and recommendations.

\section{Literature review and theoretical hypotheses}

\section{The impact of environmental regulation on carbon emission}

Environmental regulation is considered to be one of the essential means to deal with environmental problems and improve environmental quality (Hashmi and Alam 2019; Ulucak et al. 2020). Previous studies have discussed the relationship between environmental regulation and carbon emissions, but the research conclusions are inconsistent. The main viewpoints include "green paradox," emission reduction effect, and nonlinear.

\section{Green paradox}

Sinn (2008) first put forward the "green paradox," arguing that implementing strict environmental policies may damage miners' interests, which leads to increased carbon emissions from fossil energy extraction; that is to say, ER cannot availably control carbon emissions; instead, it aggravates pollution. Ritter and Schopf (2014) found that tax or alternative energy subsidy policies induced countries with less strict ER to increase the use of fossil fuels. Early or delayed implementation of environmental policies may increase energy consumption and carbon emissions (Smulders et al. 2012). Moreover, the regulatory effect of environmental policies has regional heterogeneity. With the improvement of ER, carbon emissions in most regions will rise (Wang et al. 2018b), especially in areas where the economy is depressed.

\section{Emission reduction effect}

Contrary to the view of the "green paradox," some scholars agree with the opinion of the "emission reduction effect" and believe that ER helps to reduce carbon emissions (Van der Ploeg and Withagen 2012; Pei et al. 2019; Cairns 2014; Han 2020) and the improvement of environmental regulatory quality is conducive to carbon emission reduction (Acheampong et al. 2019). At the same time, due to the differences in regulatory efficiency, regulatory costs, corporate preferences, government regulatory preferences, regulatory penalties, the scope of application, and other aspects of environmental regulation, the emission reduction effect of environmental regulation has obvious heterogeneity (Ribeiro and Kruglianskas 2015). Based on the Porter hypothesis, pollution sanctuary hypothesis, and pollution halo hypothesis, some scholars have carefully explored the emission reduction effect of environmental regulation.

On the one hand, the Porter hypothesis believes that strict and appropriate environmental regulation forces enterprises to engage in innovation, encourages enterprises to introduce advanced production technology, guides enterprises to low-carbon technology innovation (Porter and Van der Linde 1995; Pei et al. 2019), and then promotes emission reduction. The government could use environmental emission assessment and supervision, punishment system, production technology standards, and other control means to force enterprises to strengthen innovative activities (Zhao et al. 2015), aiming to achieve carbon emission reduction targets. On the other hand, strict environmental regulation forces polluters to move to areas with loose environmental regulations to reduce the cost of pollution control (Mert and Caglar 2020; Peng 2020), so areas with weak environmental regulations become pollution havens for high-carbon emission enterprises. To achieve carbon reduction targets, the government would use market means to strengthen regulation, such as fossil fuel taxes, clean development subsidies, emission charges, and trading schemes (Hashmi and Alam 2019; Wolde-Rufael and Mulat-Weldemeskel 2021), and make enterprises move to areas with lower environmental costs.

In addition, enterprises may also produce "pollution halo effect" in migration. The pollution halo hypothesis holds that the relocation of investment enterprises promotes reallocation of resources, bringing new production processes, management skills, energy conservation, and environmental protection technologies to the host country (HÜBler and Keller 2010; Mert and Caglar 2020; Liu and Xu 2021), contributes to increase output efficiency and reduce energy 
consumption, and improves environmental quality (Cole et al. 2008; Balsalobre-Lorente et al. 2019). Cole et al. (2008) investigated the impact of FDI on the environment in developing countries using Ghana's manufacturing data. They found that key employees who had received training or experience in foreign-funded companies would use what they had learned to benefit the local environment. In other words, foreign-funded enterprises could bring substantial environmental benefits to developing countries by using more advanced technology, cleaner production methods, and more advanced environmental management systems and organizational techniques. Meanwhile, the inflow of FDI improves energy efficiency, leading to a decrease in emission growth rate (HÜBler and Keller 2010; Mert and Caglar 2020). In addition, technology spillover may also be the main cause of pollution halo effect, and encouraging the use of clean technologies, increasing incentives for FDI inflows, facilitating transport infrastructure, and enhancing human capital are the necessary means for governments to address pollution and improve environmental quality (Liu and Xu 2021; Mert and Caglar 2020). For China, as the global free trade is increasingly close and a dual-cycle pattern is constructed, foreign direct investment and domestic consumption investment activities are significantly increasing. Meanwhile, due to the differences in economic development of regions, the transformation and transfer of manufacturing industries may produce a "pollution halo effect." The process of investment and transferring in manufacturing from developed areas to less developed areas may provide new production processes, technologies, and management for manufacturing in less developed areas, to some extent, which may improve the regional industrial structure, increase environmental efficiency, and thus reduce carbon emissions (Zhou et al. 2013; Li and Lin 2017b).

\section{Nonlinear influence}

Different from the above two views, the third view is that the relationship between environmental regulation and carbon emissions is nonlinear, showing a trend of first promoting and then restraining (Chen et al. 2019; Ouyang et al. 2019). That is, there is a "green paradox" effect before the inflection point and an "emission reduction reversal" effect after the inflection point (Zhang and Wei 2014), which may be due to the increased demand for highly polluting technologies and resources before the implementation of environmental policies. Pei et al. (2019) studied the industry with high energy consumption and found that the carbon reduction effect of environmental regulation is an "inverted U-shape." "Green paradox" and emission reduction effect may coexist. On the one hand, environmental regulation promotes manufacturing transformation and upgrading (Zhai and An 2020). On the other hand, environmental regulation has a nonlinear impact on carbon emissions by affecting energy consumption structure, technological innovation, foreign direct investment, and fiscal decentralization (Zhang et al. 2017; Chen et al. 2021; Wang et al. 2021)

Although studies have examined the impact of environmental regulation on carbon emissions and hold widely different views (Ritter and Schopf 2014; Hashmi and Alam 2019), few have discussed the relationship between environmental regulation and manufacturing carbon emissions. Currently, as China's economy changes from extensive growth to high-quality development (Milani 2017; Liu and $\mathrm{Xu}$ 2021), the high energy-consuming and high-emission manufacturing industry is bound to be constrained by environmental regulations. In addition, due to the spatial characteristics and complexity of atmospheric pollution (Wang et al. 2017; Ma et al. 2016), there are differences in pollution management in different regions (Feng et al. 2020). At the same time, as China's regions become increasingly economically connected, the regional transfer and transformation and upgrading of industries are accelerating, leading to an increase in the diffusion of carbon emissions and spatial aggregation. Although this adds to the complexity of environmental governance, it is reassuring to note that environmental regulation is one of the effective means of controlling carbon emissions. Enhanced regulation facilitates the convergence of carbon emissions within a certain range (Hao et al. 2020). Therefore, this paper argues that environmental regulation has an emission reduction effect on manufacturing carbon emissions and shows spatial heterogeneity due to intra-industry differences. Accordingly, this paper proposes hypothesis 1 :

H1: Environmental regulation promotes manufacturing carbon emission reduction in China and has a spatial spillover effect.

\section{The impact of local government competition on carbon emissions}

Previous studies have shown that the analysis of local government behavior from a competition perspective is an important field of environmental governance research (Yang et al. 2020). There are few studies on the relationship between LGC and carbon emissions, but they concentrate on the influence of LGC on environmental pollution. In most studies, the environment is regarded as public goods, and local governments have an inevitable responsibility towards environmental protection and quality improvement (Luo and Jiang 2017). With the continuous adjustment of the administrative and financial power between the central and local governments since the reform of the tax-sharing system, the advancement of Chinese local government officials is encouraged by both politics and economy, which makes the 
"yardstick competition" among local governments (Maskin et al. 2000), especially in environmental and economic competition (Yang et al. 2020). However, as political promotion incentives affect local governments' preferences, economic decentralization gives local governments certain financial autonomy, and "Chinese-style decentralization" makes local governments form strategic competition in implementing environmental policies (Konisky 2007).

When the local government aims at GDP growth, the performance evaluation mechanism pursues the economy ( $\mathrm{Pu}$ and Fu 2018). Political promotion is the internal incentive for local government to develop the economy in China (Zhou 2007). The central government will set up regional economic championships to mobilize regional enthusiasm (Xiong 2018). Local governments will build infrastructure on a large scale (Oates and Schwab 1988), aiming to attract enterprises with higher performance, taxes, and pollution (Cole et al. 2006), which lays the foundation for developing economy. However, with the change of economic development mode and the enhancement of public awareness of environmental protection, local governments will increase ecological performance assessment (Wu et al. 2020). Driven by environmental performance, the environmental governance of local governments presents a competitive behavior of "chasing each other" (Levinson 2003; Wu et al. 2020). When economic development is changed to environmental quality improvement, local governments will attract capital liquidity factors and promote the development of green technology to reduce environmental pollution emissions (Albornoz et al. 2009). Based on the above analysis, this paper puts forward hypothesis 2 :

H2: Local government competition will aggravate the carbon emissions of the manufacturing industry.

\section{Environmental regulation and local government competition}

The impact of environmental regulation on environmental quality depends on the local government. Previous studies have richly discussed the relationship between environmental regulation and local government competition. The existing studies are mainly based on three viewpoints: bottom-tobottom competition, top-to-top competition, and uncertainty.

\section{Bottom-to-bottom competition}

Some scholars believe that local government competition lowers environmental regulation, and the interactive behavior is "bottom-to-bottom competition" (Lai 2019; Woods 2006). The theory of environmental federalism discusses how to distribute environmental governance functions reasonably among different-level governments. Some scholars argue that the effectiveness of environmental protection functions depends on the central government, but the competition among local governments has led local governments to lower the environmental management standard in pursuit of regional economic growth (Tiebout 1956). To compete for mobility factors and solidify local resources, local governments compete to lower their levels of environmental regulation. And to maintain or attract promising enterprises and increase employment and taxes, local governments may relax environmental controls, leading to increased pollution (Zhang et al. 2017; Kunce and Shogren 2005). In the context of decentralization, environmental regulation generally presents the characteristics of "bottom-to-bottom competition" (Li et al. 2014). On the one hand, it may be due to the differences in development stages of different regions and competition at the economic level between local governments, which lower environmental standards to promote industrial development. On the other hand, it may be the "hitchhiking" behavior caused by the positive externalities of environmental governance and the government that enjoys the benefits of transboundary pollution control in neighboring areas without bearing the related costs.

\section{Top-to-top competition}

Contrary to the first group of view, some scholars also argued that decentralization does not lead to bottom-to-bottom competition (Millimet 2003; Sjöberg and Xu 2018) but rather that environmental regulatory interactions between local governments manifest as top-to-top competition (Vogel 2009; Peng 2020). The mechanism behind local governments' competition to raise their level of environmental regulation lies in local governments' adjoining and the pursuit of factors that prefer a high-quality environment. On the one hand, the collection of environmental information is characterized by economies of scale, and the central government could reduce costs by collecting and disseminating environmental information centrally; on the other hand, local governments have an advantage in collecting local environmental information and therefore have a greater ability to use it in a localized manner. Even with the same motivation of competing for mobility factors, for regions undergoing industrial restructuring, local governments tend to improve the quality of the local environment and increase the level of environmental regulation to attract mobility factors (e.g., top talent) that prefer a high-quality environment (Konisky 2007).

\section{Competition uncertainty}

In addition, some scholars have argued that there is uncertainty between environmental regulation and local government competition. Due to the heterogeneity between 
regions, neither bottom-to-bottom competition nor topto-top competition could fully summarize the interaction of environmental regulation among local governments. It may have both interactive characteristics (Konisky 2007). Zhang et al. (2010) argued that with constantly improving in the official assessment system, the impact of LGC on ER shifts from "bottom-to-bottom competition" to "top-to-top competition", and environmental governance presents nonlinear characteristics. If environmental governance has no spillover effect, the central government's environmental governance improves welfare, and local governments will seek the maximum welfare for their jurisdiction (Banzhaf and Chupp 2012). On the other hand, environmental governance has a spillover effect and diversified competition among regions, and the implementation of ER gives rise to hitchhiking behavior in environmental improvement (Wang 2015). When nearby areas intensify environmental management, local government loosens control (Sigman 2005). For transboundary pollution control, the manufacturing industry attracts more attention (Zeng and Zhao 2009). It may be a powerful way to tackle transboundary pollution to seek optimal cooperation strategy among regional local governments instead of competition (Oates 2001), such as encouraging to use negotiation, consultation, and cooperation to mediate the dilemma of multilevel governance (Ryan 2017).

As China is the environmental governance under the background of fiscal decentralization, there are obvious problems of interest coordination in different regions, which leads to different efforts in environmental governance. With the construction of China's dual-cycle pattern and the continuous promotion of manufacturing transformation and upgrading, the relocation of manufacturing activities has increased. Driven by the Chinese government's commitment to achieving carbon emission reduction targets, environmental constraints promote the entry threshold of manufacturing migration and transformation. At this point, local government competition is no longer a single pursuit of economic growth but a "top-to-top competition" that includes strengthening ecological performance assessment and environmental protection. Therefore, this paper puts forward hypothesis 3 :

H3: Under the restriction of environmental regulation, local government competition is conducive to manufacturing carbon emission reduction, showing "top-to-top competition."

In summary, most existing studies have explored interactive relations between ER, LGC, and carbon emissions. However, few studies investigate manufacturing from the micro-level, which hinders the detailed understanding of emission reduction in manufacturing segments. Second, in terms of research content, few studies incorporate the three into a unified framework. With the gradual expansion of the regional development gap, the dynamic adjustment of local government competition and environmental regulation interacts more closely. Therefore, it is needed to explore the influence mechanism, spatial spillover effect, and attenuation boundary of ER on MCE from the perspective of LGC. Third, most researchers employ static or dynamic panel models, neglecting the spatial correlation and spillover on carbon emissions. The transmission of carbon emissions among areas has a strong spatial correlation and dependence (Zhao et al. 2014), and ignoring the spatial characteristics of the research object may cause bias in the regression (Cheng 2016; Sun et al. 2015). This study is of significance to deeply explore the influence of ER on MCE from the perspective of LGC, and it is needed for the government to formulate reasonable, targeted, and differential environmental policies to reduce MCE.

\section{Methodology and data}

\section{Model selection}

\section{Spatial correlation}

To identify the spatial correlation of MCE, this paper used Moran's I tests.

\section{(1) Global Moran's I}

Referring to Geniaux and Martinetti (2018), the calculation formula is as follows:

$I_{G}=\frac{\sum_{i=1}^{n} \sum_{i \neq j}^{n} W_{i j}\left(x_{i}-\bar{x}\right)\left(x_{j}-\bar{x}\right)}{\sum_{i=1}^{n}\left(x_{i}-\bar{x}\right)^{2}}$

where $x_{i}$ and $x_{j}$ are observed values, $n$ is sample number, $\bar{x}$ is the sample mean, and $W_{i j}$ is spatial weight matrix. Since the adjacent space weight matrix represents the interrelationship of regional observations only according to whether the spatial units are adjacent or not, it cannot reflect the spatial units that are geographically close but not directly connected. Therefore, following the work of Wang and Zhu (2020), the geographical distance weight matrix is constructed using the reciprocal distance between provinces in this paper, and the following formula is used.

$$
W_{i j}=\left\{\begin{array}{c}
1 / d_{i j} i \neq j \\
0 i=j
\end{array}\right.
$$

where $d_{i j}$ is the geospatial distance between provinces $i$ and $j$, which is evaluated by the latitude and longitude of the capital cities of provinces $i$ and $j$.

(2) Local Moran's I 
In order to clarify the local spatial connection, this paper adopts local Moran's I index. The formula is calculated as:

$$
I_{L}=\frac{n\left(x_{i}-\bar{x}\right) \sum_{j=1}^{n} W_{i j}\left(x_{j}-\bar{x}\right)}{\left(x_{i}-\bar{x}\right)^{2}}
$$

In local Moran's I test, the $\mathrm{H}-\mathrm{H}$ and L-L agglomeration indicates that the regions with high (low) MCE are encircled by areas with high (low) MCE. In contrast, $\mathrm{H}-\mathrm{L}$ and $\mathrm{L}-\mathrm{H}$ agglomeration indicates that high (low) MCE regions are surrounded by low (high) MCE regions.

\section{Spatial econometric model}

The existing studies on the relationship between human activities and the ecological environment mostly adopt the IPAT model of Ehrlich and Holdren (1971) to discuss the effect of the population $(P)$, affluence $(A)$, and technology $(T)$ on the environment $(I)$, as shown in formula (4). Since the regression results caused by spatial correlation are biased, the revised STIRPAT model (Anselin 1989) is used to determine the impact of ER on MCE, as shown in formula (5):

$I=P A T$

$I_{i t}=a_{i} P_{i t}^{b} A_{i t}^{c} T_{i t}^{d} e_{i t}$

where $I_{i t}, P_{i t}, A_{i t}$, and $T_{i t}$ represent the environmental impact $(I)$, population size $(P)$, affluence $(A)$, and technology $(T)$ of the $i$ province in $t$ year, respectively; $a_{i}$ is the model coefficient; $b, c$, and $d$ are parameters to be estimated; and $e_{i t}$ stands for the random disturbance. In order to test the influence of ER on MCE, this research refers to the previous studies, including important factors such as per capital GDP (PGDP), opening degree (OD), unemployment rate (UR), fiscal expenditure scale (FES), and public facilities investment (PFI) into the model (Cheng et al. 2021; Banerjee et al. 2020; Xin et al. 2020). In addition, due to different government goals, government competition behavior leads to different intensities of ER, which further affects MCE. Therefore, local government competition and environmental regulation $(\mathrm{LGC} \times \mathrm{ER})$ are incorporated into formula (5), and logarithmic processing is carried out to obtain model (6):

$$
\begin{gathered}
\ln M C E=\lambda_{0}+\lambda_{1} \ln E R_{i t}+\lambda_{2} \ln L G C_{i t}+\lambda_{3} \ln L G C_{i t} \times E R_{i t}+\lambda_{4} \ln P G D P_{i t}+\lambda_{5} \ln O D_{i t} \\
+\lambda_{6} \ln U R_{i t}+\lambda_{7} \ln F E S_{i t}+\lambda_{8} \ln P F I_{i t}+e_{i t}
\end{gathered}
$$

where MCE represents the manufacturing carbon emissions; $\lambda_{0}$ is the constant; $\lambda_{1}, \lambda_{2}, \lambda_{3}, \lambda_{4}, \lambda_{5}, \lambda_{6}, \lambda_{7}$, and $\lambda_{8}$ represent the coefficients to be estimated; and $e_{i t}$ stands for the random error.

In order to empirically test the spatial spillover effect and attenuation boundary of environmental regulation on manufacturing carbon emissions, the spatial Durbin model (SPDM) is constructed as follows:

$$
\begin{aligned}
\ln M C E_{i t} & =\rho \sum_{i=1}^{n} W_{i j} \ln M C E_{i t}+\delta_{1} \sum_{i=1}^{n} W_{i j} \ln E R_{i t}+\delta_{2} \sum_{i=1}^{n} W_{i j} \ln L G C_{i t} \\
& +\delta_{3} \sum_{i=1}^{n} W_{i j} \ln L G C_{i t} \times E R_{i t}+\delta_{4} \sum_{i=1}^{n} W_{i j} \ln P G D P_{i t} \\
& +\delta_{5} \sum_{i=1}^{n} W_{i j} \ln O D_{i t}+\delta_{6} \sum_{i=1}^{n} W_{i j} \ln U R_{i t}+\delta_{7} \sum_{i=1}^{n} W_{i j} \ln F E S_{i t} \\
& +\delta_{8} \sum_{i=1}^{n} W_{i j} \ln P F I_{i t}+\lambda_{0}+\lambda_{1} \ln E R_{i t}+\lambda_{2} \ln L G C_{i t} \\
& +\lambda_{3} \ln L G C_{i t} \times E R_{i t}+\lambda_{4} \ln P G D P_{i t}+\lambda_{5} \ln O D_{i t}+\lambda_{6} \ln U R_{i t} \\
& +\lambda_{7} \ln F E S_{i t}+\lambda_{8} \ln P F I_{i t}+u_{i t}+e_{i t}
\end{aligned}
$$

where $W_{i j}$ represents the spatial weight matrix; $\rho$ is the spatial coefficient of the explained variables; $\delta_{1}, \delta_{2}, \delta_{3}, \delta_{4}, \delta_{5}$, $\delta_{6}, \delta_{7}$, and $\delta_{8}$ are the spatial coefficients of the explanatory variables and control variables; $u_{i t}$ is the individual fixed effect; and $e_{i t}$ stands for the random error. The research framework is shown in Fig. 1.

\section{Decomposition of direct and indirect effects}

In order to explore the spatial spillover effect of ER on MCE, partial differentiation is employed to decompose the direct and indirect effects. Based on LeSage and Pace (2009), the SPDM model is converted as follows:

$Y_{i t}=\left(I_{N T}-\rho W_{i j}\right)^{-1} X_{i t}\left(I_{N T} \beta+W_{i j} \delta\right)+\left[I_{N T}-\rho W_{i j}\right]^{-1} \varepsilon_{i t}$

where $Y$ is the vector of $N \times 1$ dimensional dependent variable and $I_{N T}$ represents $N \times T$ dimensional matrix. The partial derivative of $X$ is as follows:

$M E M=\frac{\partial Y_{i t}}{\partial X_{i t}}=\left(I_{N T}-\rho W_{i j}\right)^{-1}\left(I_{N T} \beta+W_{i j} \delta\right)$

$$
\begin{gathered}
M E_{\text {Total }}=\frac{1}{N T} l(M E M), l=\text { ones }(N T, 1) \\
M E_{\text {Direct }}=\frac{1}{N T} \operatorname{Trace}(M E M) \\
M E_{\text {Indirect }}=M E_{\text {Total }}-M E_{\text {Direct }}
\end{gathered}
$$




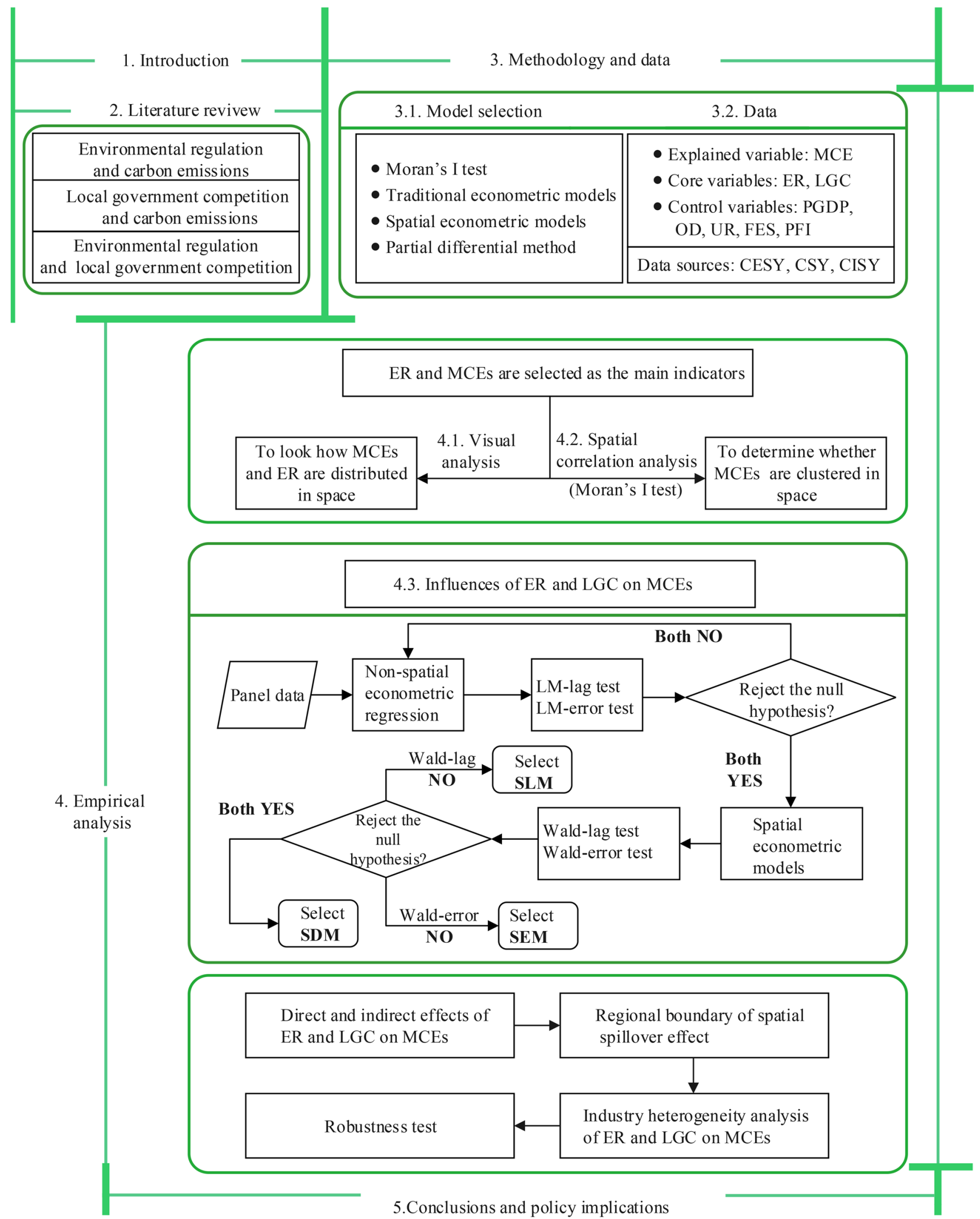

Fig. 1 Research framework 


\section{Data}

\section{Explained variable: manufacturing carbon emissions (MCE)}

Based on data availability and authenticity, the carbon emission coefficient method is adopted to calculate MCE in this study. According to the calculation method of IPCC (2007), MCE in China's provinces is measured as follows:

$M C E=\sum_{i}^{30} \sum_{j}^{17} M C E_{i j}=\sum_{i}^{30} \sum_{j}^{17} F_{i j} \times C V_{j} \times C \mathrm{EF}_{j} \times C \mathrm{OF}_{j} \times \frac{44}{12}$

among them, $i=1,2 \ldots, 30$ represents the manufacturing sector; $j=1,2 \ldots, 17$ denotes the type of energy; $M C E$ is the total manufacturing carbon emission; $F$ is terminal fossil energy consumption; and $C V$ represents the average low calorific value of different fossil fuels. $C E F$ is the carbon content of the fuel, $C O F$ is the oxidation efficiency of energy, and $44 / 12$ is the ratio of $\mathrm{CO}_{2}$ to carbon molecular weight.

\section{Explanatory variable: environmental regulation (ER)}

Existing studies mainly have two perspectives to measure ER. First, from the standpoint of cost and expense, the study holds that the investment of pollution management is positively related to the intensity of ER; that is, the higher the percentage of industrial cost in controlling pollution, the more conducive to environmental protection (Cheng et al. 2017). Second, based on the perspective of pollution emissions, some scholars use the proportion of industrial sulfur dioxide, smoke (dust), and other pollutants in the total emissions to measure ER (Li et al. 2021 b; Du and Li 2020). However, to a large extent, these indicators reflect the production and emission stages of carbon dioxide, causing endogeneity. To avoid biased estimation caused by such defects, some scholars study from the perspective of environmental performance and believe that the pollution-controlling effectiveness can better stand for the degree of ER (Wu et al. 2020; Ge et al. 2020; Ge and Li 2020). Thus, the removal efficiency and utilization of pollutants are crucial measurements in ER. Based on the measurement method by Ge and Li (2020), this paper selects the removal rate of industrial sulfur dioxide, treatment rate of industrial effluents, the comprehensive utilization rate of industrial solid waste, and decontamination rate of domestic waste and uses the entropy method to calculate ER.

\section{Moderating variable: local government competition (LGC)}

Local government competition refers to the behavior that different economies within a region adopt the tax, fiscal expenditure, environmental policies, and other means to attract mobility factors such as capital and labor to enhance their competitive advantage (Breton 1998). Regional economic catch-up is an obvious manifestation of LGC. Referring to the calculation methods by Hong et al. (2020), the economic catch-up level is jointly determined by neighboring provinces and the whole country as the proxy variable of LGC. The calculation method is as follows:

$L G C_{i t}=\left[\max \left(m g d p_{i t}\right) / a g d p_{i t}\right] *\left[\max (g d p) / a g d p_{i t}\right]$

among them, $\max \left(m g d p_{i t}\right)$ represents the highest GDP of neighboring provinces except for province $i$ in $t$ year; $a g d p_{i t}$ represents the GDP of the province $i$ in $t$ year; and $\max (g d p)$ represents the highest GDP of each province.

\section{Control variables}

In order to control the impact of economy, population, technology, and other factors on manufacturing carbon emissions, this study chooses the following control variables: (1) Per capital GDP (PGDP): economic growth is regarded as one of the essential elements of environmental governance (Saint Akadiri et al. 2020; Baloch et al. 2021), so per capita GDP is employed to stand for economic development. (2) Opening degree (OD): the economic opening contributes to the incentive economy ( $\mathrm{Li}$ and Wei 2021; Alam and Murad 2020). The economic opening increases economic activities and energy consumption and further affects environmental quality, so the percentage of social total retail sales of consumer goods in GDP is chosen to represent opening degree. (3) Unemployment rate (UR): changes in the employed and unemployed population affect resource consumption. Excessive growth or unreasonable development mode further causes environmental damage (Yuan et al. 2020), which has a significant influence on environmental improvement. Therefore, the representation of the urban registered unemployment rate is adopted. (4) Fiscal expenditure scale (FES): fiscal expenditure is a way to invest in environmental governance (Khan et al. 2021; Cheng et al. 2021); the appropriate scale of fiscal expenditure is conducive to improving resource utilization efficiency and environmental performance, so the proportion of government expenditure in GDP is selected to measure fiscal expenditure scale. (5) Public facilities investment (PFI): public infrastructure investment affects the efficiency of resource allocation because infrastructure reduces transportation costs and promote information exchange (Banerjee et al. 2020; Wang et al. 2020; Anser et al. 2021); public facilities affect transaction costs, which in turn affect environmental quality, so this study uses the number of hospitals per 10,000 people to control its impact on MCE. The specific variable definitions are shown in Table 1. 
Table 1 Descriptive statistics of the main variables

\begin{tabular}{lllrlrr}
\hline Variables & Notation & Unit & Mean & Max & Min & \multicolumn{2}{c}{ S.D } \\
\hline Manufacturing carbon emissions & MCE & Million tons & 97.21 & 490.30 & 3.73 & 77.33 \\
Environmental regulation & ER & $\%$ & 6.63 & 33.04 & 0.88 & 6.25 \\
Local government competition & LGC & $\%$ & 51.57 & 661.7 & 0.29 & 134.01 \\
Per capital GDP & PGDP & Yuan & $44,232.02$ & 164,563 & 7778 & $26,567.58$ \\
Opening degree & OD & $\%$ & 0.39 & 0.61 & 0.25 & 0.06 \\
Unemployment rate & UR & $\%$ & 3.39 & 4.60 & 1.20 & 0.66 \\
Fiscal expenditure scale & FES & $\%$ & 0.25 & 0.76 & 0.10 & 0.11 \\
Public facilities investment & PFI & $/ 100,000$ persons & 6.38 & 12.06 & 1.23 & 2.79 \\
\hline
\end{tabular}

\section{Data source}

This paper selects the manufacturing panel data of 30 provinces in China (except Tibet, Hong Kong, Macao, and Taiwan) from 2007 to 2019. The data comes from China Statistical Yearbook, China Environmental Statistical Yearbook, China Energy Statistical Yearbook, and China Industrial Statistical Yearbook. The data of geographic information comes from the 1: 4,000,000 databases of the National Geographic Information Center.

\section{Empirical results}

\section{Temporal and spatial evolution analysis}

\section{Temporal characteristics analysis}

From the time dimension, the trend of MCE and ER is shown in Fig. 2. From 2007 to 2019, MCE showed a warptail shape, and ER was stable and increased on the whole.
Both MCE and ER show stage characteristics and regional differences are gradually increasing.

In the growth stage (2007-2014), MCE increased from 70.76 to $109.29 \mathrm{Mt}$, an increase of $54.41 \%$. It may be that rapidly manufacturing development is accompanied by environmental pollution. In the decline stage (2014-2019), MCE decreased from 109.29 to $101.95 \mathrm{Mt}$, decreasing $6.72 \%$. Concerning ER, in the "U-shaped" stage (2007-2010), the index first decreased from 6.51 to 5.96 and then increased to 6.41. During the period of fluctuating growth (2010-2019), the fluctuation increased from 6.41 to 7.24 , an increase of $12.95 \%$, and maintained a steady and growing trend as a whole.

From the perspective of regions, the rank of mean values (from high to low) in MCE was the east, the middle, the nation, and the west, and the trend of different regions was the same, showing an increase and then decrease. However, as time went on, the gap in MCE between the east and the west increased from 58.79 to $63.25 \mathrm{Mt}$, increasing by $7.59 \%$. The gap between the east and the middle increased from 18.38 to $30.95 \mathrm{Mt}$, increasing by $68.39 \%$. The regional
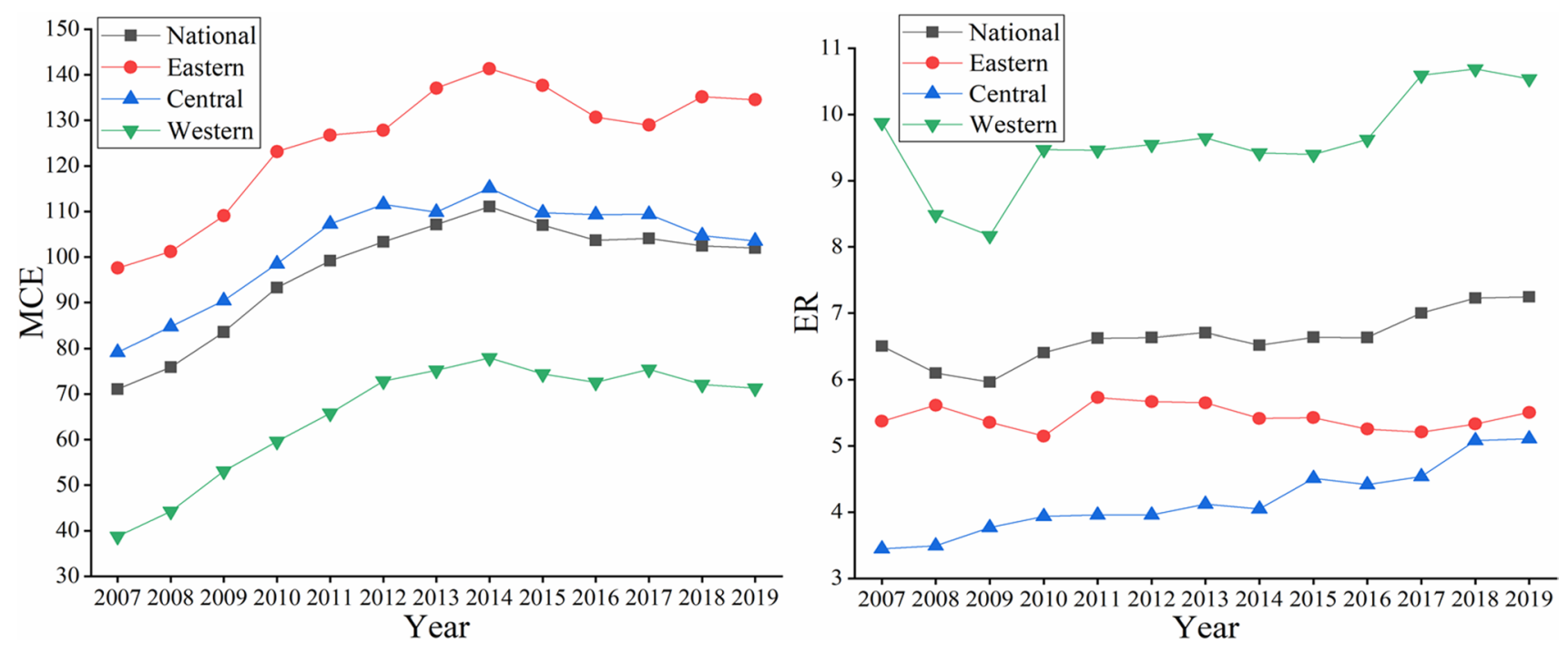

Fig. 2 Temporal evolution characteristics of MCE and ER from 2007 to 2019 in China 
difference was gradually enlarged, and the phenomenon of "polarization" is aggravating. The intensity of ER from strong to weak was the west, nation, east, and middle. The changes are stable in the east and the middle and fluctuate in the west, showing an overall growth trend. MCE and ER are characterized by regional differentiation and interaction, a benign interaction of "high ER-low MCE," and show that improving ER contributes to MCE reduction.

\section{Spatial characteristics analysis}

ArcGIS 10.3 is adopted to clarify the spatial heterogeneity of MCE and ER in different regions. As shown in Fig. 3, MCE was decreasing step by step from east to west. The high MCE area expanded from Hebei-Shandong concentrated distribution to Hebei-Shandong-Liaoning-Jiangsu-HenanShanxi-Sichuan connected area, which spread from the eastern coast to the southwest. The spatial range of higher MCE areas gradually grew and extended from the east to the central region and evolved from sporadic point distribution to clustered contiguous distribution. The spatial scope of lower and low MCE decreased significantly, with the proportion decreasing from 76.67 to $53.33 \%$, and the spatial distribution evolved from aggregation to divergence. Overall, MCE extended from east to west, which may be attributed to the State Council in China explicitly proposing in 2010 that industries be transferred to the middle and west, including high-tech and traditional manufacturing industries such as building materials and chemical industry. The manufacturing transfer is accompanied by the pollution transfer, which intensifies carbon emissions.

ER shows a differentiation pattern of "high in the northwest and low in the southeast," and ER is gradually strengthened. The spatial pattern of strict and weak ER is relatively stable, and the stricter ER evolved from a "single core" pattern dominated by "Yunnan-Guangxi-Chongqing" to a
Fig. 3 Spatial characteristics of MCE and ER from 2007 to 2019 in China
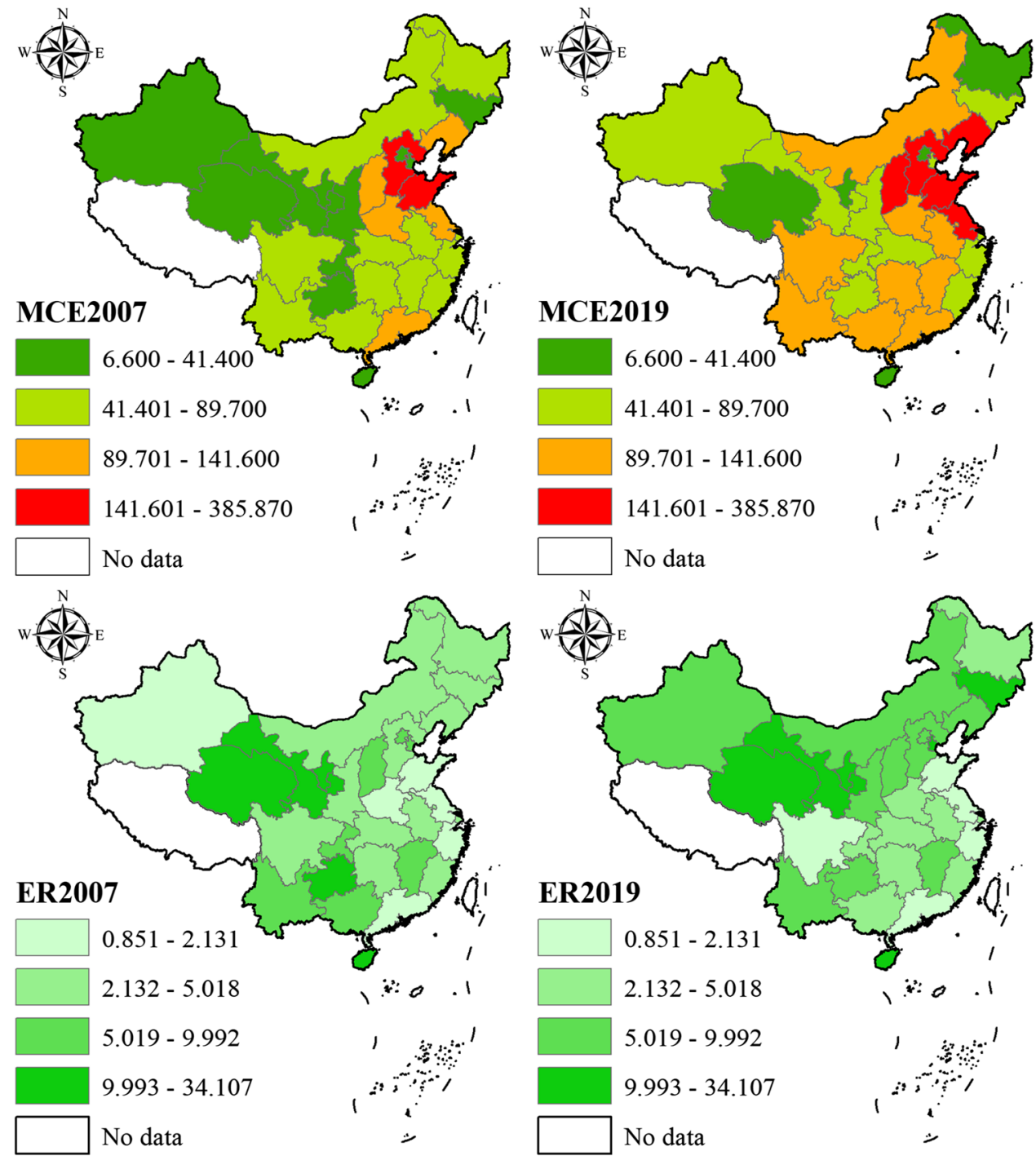
Table 2 Moran's I index of MCE from 2007 to 2019 in China

\begin{tabular}{|c|c|c|c|c|c|c|c|c|c|c|c|c|c|}
\hline Year & 2007 & 2008 & 2009 & 2010 & 2011 & 2012 & 2013 & 2014 & 2015 & 2016 & 2017 & 2018 & 2019 \\
\hline Moran's I & $0.283^{* * * *}$ & $0.231^{* *}$ & $0.197^{* *}$ & $0.162^{* *}$ & $0.156^{* *}$ & $0.131^{*}$ & $0.120^{*}$ & $0.124^{*}$ & $0.134^{*}$ & 0.102 & 0.066 & 0.094 & 0.084 \\
\hline$Z$ value & 2.906 & 2.250 & 1.948 & 1.673 & 1.678 & 1.438 & 1.386 & 1.392 & 1.466 & 1.207 & 0.878 & 1.278 & 1.246 \\
\hline
\end{tabular}

Note: $* * *$, and $* * *$ indicate significance at the $10 \%, 5 \%$, and $1 \%$ levels, respectively

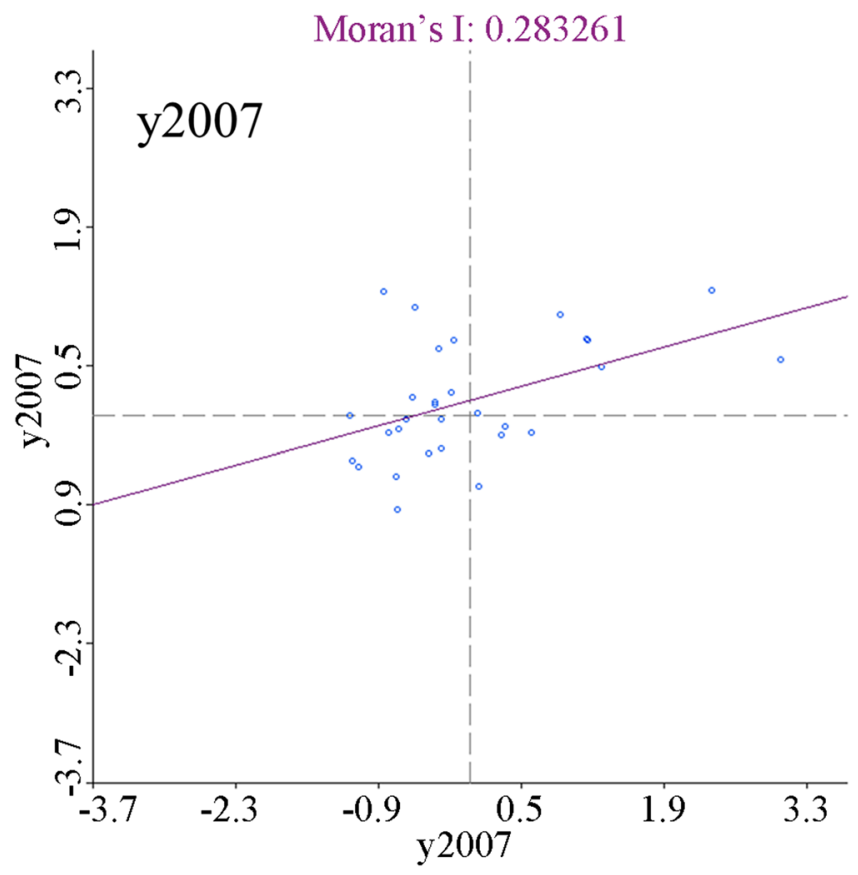

Fig. 4 Moran's I scatterplot of MCE from 2007 to 2019 in China

dual-core distribution formed by "Jilin-Liaoning-BeijingTianjin-Hebei-Shanxi-Inner Mongolia." The spatial scope of weaker ER is significantly reduced, which evolved from centralized distribution to divergent and sporadic distribution. In general, the spatial differentiation pattern may be attributed to the differences in the implementation of ER by local governments. The economic development in the east and middle is relatively better; the rapid manufacturing development is accompanied by the increase of pollution, which exacerbates the difficulty to improve the role of ER in a short time and results in weak ER in the east.

\section{Spatial correlation analysis}

Global Moran's I results of MCE in China from 2007 to 2019 are shown in Table 2 . Moran's $I$ values are significantly positive at $5 \%$, decreasing from 0.283 to 0.084 , revealing that MCE has a significant positive spatial correlation. The regions with higher and lower MCE tend to be concentrated, but their spatial dependence gradually decreases. Therefore,

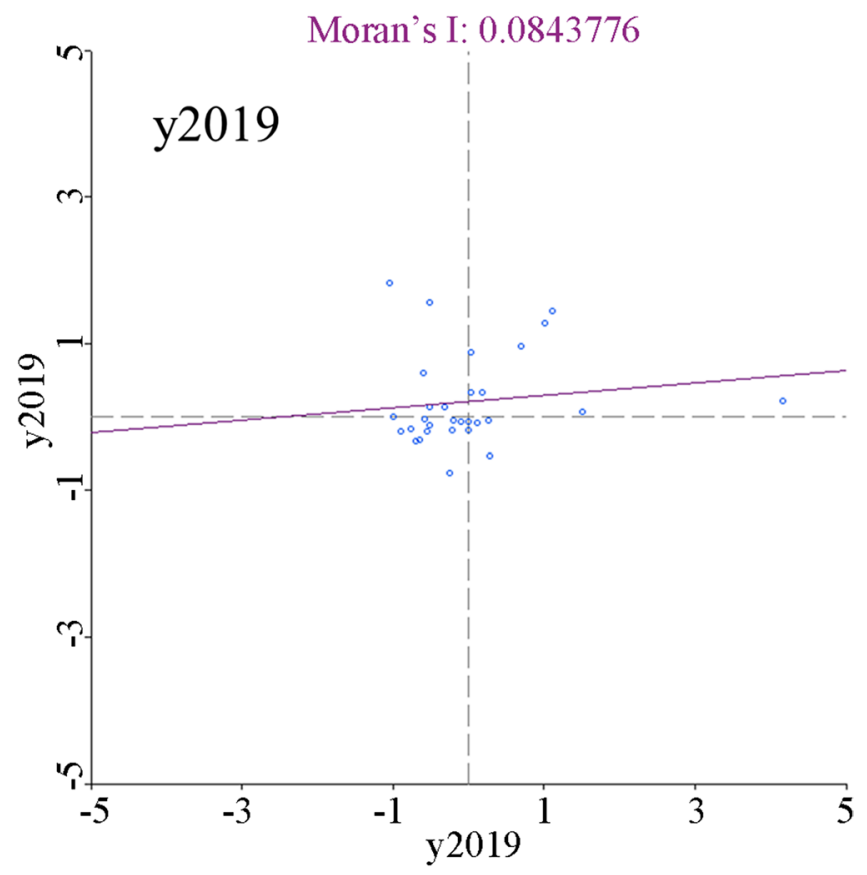

the spatial effect should be considered to study the influence mechanism.

In order to effectively describe the spatial heterogeneity of MCE at the local scale, local spatial autocorrelation is used for further examination. Figure 4 indicates that the regional spatial correlation characteristics in MCE are dominated by $\mathrm{H}-\mathrm{H}$ and $\mathrm{L}-\mathrm{L}$ agglomeration. As the agglomeration degree becomes more evident, the polarization trend gradually appears, so there is a need to adopt the spatial econometric model to explore the relationship among the three.

\section{Estimation result analysis}

\section{Result of model selection}

The results of the spatial econometric model are shown in Table 3. LM test results demonstrate that SPLM and SPEM are applicable to examine the relationship between ER and MCE. Wald and LR test prove SPDM is most suitable for exploring the influence of ER on MCE. In addition, 
Table 3 Identification test of spatial panel econometrics model

\begin{tabular}{lrll}
\hline Tests & Statistics & Tests & Statistics \\
\hline LM(lag) test & $19.753^{* * * *}$ & Wald_spatial_lag & $56.540^{* * *}$ \\
Robust LM(lag)test & $5.188^{* * *}$ & LR_spatial_lag & $52.620^{* * *}$ \\
LM(error)test & $18.021^{* * *}$ & Wald_spatial_error & $69.711^{* * *}$ \\
Robust LM(error)test & $3.456^{* * *}$ & LR_spatial_error & $59.090^{* * *}$ \\
Hausman test & $25.512^{* * *}$ & & \\
\hline
\end{tabular}

Note: $* * *$, and $* * *$ indicate significance at the $10 \%, 5 \%$ and $1 \%$ levels, respectively

the Hausman test demonstrates that the fixed effect model should be chosen. Therefore, this study adopts SPDM with a fixed effect to examine the influence of ER on MCE.

\section{Results of the spatial Durbin model}

The results in Table 4 show that the Spatial rho of time fixed and spatial-time fixed has passed the significance test. Considering $R^{2}$ and Variance Sigma2_e, this study selects SPDM of time fixed effect as the optimal fitting mode.

The ER coefficient is -0.104 at the significance level of $1 \%$, indicating that ER significantly inhibits MCE. The conclusion is in agreement with the views of Cheng et al. (2017) and Pei et al. (2019), which may be that government effectively reduces MCE through environmental regulatory measures such as emission taxes and environmental protection subsidies (Zhao et al. 2015). On the other hand, the result also verifies the Porter hypothesis (Porter and Van der Linde 1995), the strengthening of ER forces enterprises to make technological innovations and introduce green processes (Yang et al. 2012), which aims to improve energy efficiency and reduce MCE. The coefficient of LGC is 0.011 and passes the 5\% significant level, which indicates that LGC significantly promotes MCE. It may be because local governments, in pursuit of economic growth and political performance, prioritize attracting enterprises with high output value and high income. However, these enterprises are often accompanied by high energy consumption and pollution, which increases the manufacturing carbon emission while achieving economic benefits. The adjustment coefficient of LGC is -0.038 and passes the $10 \%$ significant level, which shows that when considering the combined effect of ER and LGC, LGC strengthens the restraining influence of ER on MCE. This may be because the assessment of local government officials has changed from a single promotion incentive with GDP growth to a multiple promotion incentive with environmental performance. In addition, it may also be the change of local government behavior mode; in the post-COVID-19 era, an increasing number of countries have begun to pay attention to environmental problems in the process of economic development (Dou et al. 2021), and the improvement
Table 4 Estimation results of the spatial Durbin model

\begin{tabular}{|c|c|c|c|}
\hline Variables & $\begin{array}{l}\text { (1) } \\
\text { Spatial fixed }\end{array}$ & $\begin{array}{l}\text { (2) } \\
\text { Time fixed }\end{array}$ & $\begin{array}{l}\text { (3) } \\
\text { Spatial-time fixed }\end{array}$ \\
\hline $\ln E R$ & $\begin{array}{l}-0.066^{* * *} \\
(-4.30)\end{array}$ & $\begin{array}{l}-0.104^{* * *} \\
(-6.36)\end{array}$ & $\begin{array}{l}-0.077^{* * *} \\
(-5.06)\end{array}$ \\
\hline $\ln L G C$ & $\begin{array}{l}0.029^{* * *} \\
(7.41)\end{array}$ & $\begin{array}{l}0.011^{* *} \\
(2.04)\end{array}$ & $\begin{array}{l}0.024^{* * * *} \\
(5.80)\end{array}$ \\
\hline $\ln E R \times L G C$ & $\begin{array}{l}-0.595^{* * *} \\
(-7.97)\end{array}$ & $\begin{array}{l}-0.038^{*} \\
(-1.83)\end{array}$ & $\begin{array}{l}-0.554^{* * *} \\
(-7.63)\end{array}$ \\
\hline $\ln P G D P$ & $\begin{array}{l}-0.173^{* * *} \\
(-3.29)\end{array}$ & $\begin{array}{l}-0.121^{*} \\
(-1.68)\end{array}$ & $\begin{array}{l}-0.220^{* * *} \\
(-4.05)\end{array}$ \\
\hline $\ln O D$ & $\begin{array}{l}0.031 \\
(1.39)\end{array}$ & $\begin{array}{l}0.168^{* * *} \\
(3.89)\end{array}$ & $\begin{array}{l}0.030 \\
(1.41)\end{array}$ \\
\hline $\ln U R$ & $\begin{array}{l}0.003 \\
(0.15)\end{array}$ & $\begin{array}{l}0.065^{* *} \\
(2.35)\end{array}$ & $\begin{array}{l}0.016 \\
(0.73)\end{array}$ \\
\hline $\ln F E S$ & $\begin{array}{l}-0.143^{*} \\
(-1.94)\end{array}$ & $\begin{array}{l}-0.535^{\text {*** }} \\
(-6.17)\end{array}$ & $\begin{array}{l}-0.230^{* * *} \\
(-3.05)\end{array}$ \\
\hline $\ln P F I$ & $\begin{array}{l}0.005^{* *} \\
(2.13)\end{array}$ & $\begin{array}{l}0.029^{* * *} \\
(9.56)\end{array}$ & $\begin{array}{l}0.005^{*} \\
(1.88)\end{array}$ \\
\hline$W \times \ln E R$ & $\begin{array}{l}0.050^{* *} \\
(1.96)\end{array}$ & $\begin{array}{l}0.009^{*} \\
(1.69)\end{array}$ & $\begin{array}{l}0.002 \\
(0.06)\end{array}$ \\
\hline$W \times \ln L G C$ & $\begin{array}{l}0.003 \\
(0.38)\end{array}$ & $\begin{array}{l}0.031^{* * *} \\
(3.19)\end{array}$ & $\begin{array}{l}0.018^{* *} \\
(2.25)\end{array}$ \\
\hline$W \times \ln E R \times L G C$ & $\begin{array}{l}-0.150 \\
(-1.01)\end{array}$ & $\begin{array}{l}-0.394^{*} \\
(-1.84)\end{array}$ & $\begin{array}{l}-0.205 \\
(-1.36)\end{array}$ \\
\hline$W \times \ln P G D P$ & $\begin{array}{l}0.219^{* * *} \\
(3.49)\end{array}$ & $\begin{array}{l}0.597^{* * *} \\
(3.57)\end{array}$ & $\begin{array}{l}0.135 \\
(1.34)\end{array}$ \\
\hline$W \times \ln O D$ & $\begin{array}{l}0.025 \\
(0.72)\end{array}$ & $\begin{array}{l}0.049 \\
(0.68)\end{array}$ & $\begin{array}{l}0.013 \\
(0.38)\end{array}$ \\
\hline$W \times \ln U R$ & $\begin{array}{l}0.051 \\
(1.17)\end{array}$ & $\begin{array}{l}-0.033 \\
(-0.56)\end{array}$ & $\begin{array}{l}0.088 \\
(1.53)\end{array}$ \\
\hline$W \times \ln F E S$ & $\begin{array}{l}0.451^{* * *} \\
(3.81)\end{array}$ & $\begin{array}{l}0.074 \\
(0.45)\end{array}$ & $\begin{array}{l}0.129 \\
(0.86)\end{array}$ \\
\hline$W \times \ln P F I$ & $\begin{array}{l}-0.003 \\
(-1.13)\end{array}$ & $\begin{array}{l}0.021^{* *} \\
(2.33)\end{array}$ & $\begin{array}{l}0.006 \\
(1.00)\end{array}$ \\
\hline Spatial rho & $\begin{array}{l}0.029 \\
(0.42)\end{array}$ & $\begin{array}{l}0.154^{* *} \\
(2.16)\end{array}$ & $\begin{array}{l}-0.097^{*} \\
(-1.77)\end{array}$ \\
\hline Variance sigma2_e & $\begin{array}{l}0.001^{* * *} \\
(13.96)\end{array}$ & $\begin{array}{l}0.010^{* * *} \\
(13.89)\end{array}$ & $\begin{array}{l}0.001^{\text {**** }} \\
(13.95)\end{array}$ \\
\hline$R^{2}$ & 0.033 & 0.484 & 0.182 \\
\hline$N$ & 390 & & \\
\hline
\end{tabular}

Note: $* * *$, and $* * *$ indicate significance at the $10 \%, 5 \%$, and $1 \%$ levels, respectively. The $t$ values are in parentheses

of environmental governance ability has gradually become a new goal of local government competition.

The control variables show that the per capital GDP (PGDP) coefficient is -0.121 at the significance level of $10 \%$, illustrating that China's economic transformation is undergoing changes from extensive development to intensive development, which is helpful in high-quality economic 
development and MCE reduction. The opening degree (OD) coefficient is 0.168 at the significance level of $1 \%$, which shows that with the improvement of domestic opening up, economic activities become more frequent, and expanding domestic demand leads to an increase in industrial production, resulting in more energy consumption and carbon emissions. The coefficients of the unemployment rate (UR) and public facilities investment (PFI) are respectively 0.065 and 0.029 , both of which are significant at the $5 \%$ level, indicating that labor shortage and infrastructure increase have an impact on manufacturing production, which may aggravate industrial structural contradiction, resulting in increased resource consumption and reduced utilization efficiency, thus increasing manufacturing carbon emissions. The coefficient of the fiscal expenditure scale (FES) is -0.535 and passed the $1 \%$ significance test, indicating that the increase in the fiscal expenditure scale may increase investment in environmental governance and thus reduce carbon emissions.

In terms of spatial effect, the spatial interaction coefficients of ER, LGC, PGDP, and FES are 0.009, 0.031, 0.597, and 0.021 , respectively, which indicates these factors have a significant positive spatial effect on MCE. The moderation coefficient of LGC is -0.394, which is significant at the level of $10 \%$, indicating that the regulatory effect of LGC shows a negative spatial effect. However, since the point estimate regression results may be biased, this paper uses the partial differential method of Lesage and Pace (2009) to decompose the spatial effect and further investigate the spatial spillover effect of each variable on manufacturing carbon emissions.

Table 5 Result of effect decomposition

\begin{tabular}{llcl}
\hline Variable & Direct effect & Indirect effect & Total effect \\
\hline $\ln E R$ & $-0.104^{* * *}$ & $0.026^{* *}$ & $-0.078^{* * *}$ \\
& $(-6.05)$ & $(1.70)$ & $(-2.82)$ \\
$\ln L G C$ & $0.012^{* * *}$ & $0.038^{* * *}$ & $0.050^{* * *}$ \\
& $(2.62)$ & $(3.62)$ & $(4.04)$ \\
$\ln E R \times L G C$ & $-0.026^{*}$ & $-0.468^{*}$ & $-0.494^{*}$ \\
& $(-1.72)$ & $(-1.87)$ & $(-1.77)$ \\
$\ln P G D P$ & $-0.097^{*}$ & $0.664^{* * *}$ & $0.567^{* * *}$ \\
& $(-1.66)$ & $(3.55)$ & $(3.50)$ \\
$\ln O D$ & $0.166^{* * *}$ & 0.021 & $0.187^{*}$ \\
& $(3.96)$ & $(0.28)$ & $(1.73)$ \\
$\ln U R$ & $0.066^{* *}$ & -0.023 & 0.043 \\
& $(2.41)$ & $(-0.33)$ & $(0.56)$ \\
$\ln F E S$ & $-0.540^{* * *}$ & 0.012 & $-0.528^{* * *}$ \\
& $(-6.49)$ & $(0.07)$ & $(-3.22)$ \\
$\ln P F I$ & $0.030^{* * *}$ & $0.030^{* * *}$ & $0.060^{* * *}$ \\
& $(10.87)$ & $(3.21)$ & $(6.18)$ \\
\hline
\end{tabular}

Note: $*, * *$, and $* * *$ indicate significance at the $10 \%, 5 \%$ and $1 \%$ levels, respectively. The $t$ values are in parentheses

\section{Result of direct and indirect effects}

The above research found that the spatial coefficients of all variables passed the significance test, and the total effect is further decomposed, shown in Table 5. The direct effect of ER is -0.104 , which passes the significance level of $1 \%$, showing that ER significantly inhibits local MCE. It may be that the government strengthens ER, prompting some polluting enterprises to migrate (Peng 2020) and forcing other enterprises to innovate green technology (Zhang et al. 2020), which is helpful to reduce local MCE. The spillover coefficient of ER is 0.026, passing the significance level of $10 \%$, which shows that strengthening local ER will increase adjacent MCE, revealing that stringent local ER forces manufacturers to reduce the pollution control cost and migrate to surrounding areas with loose ER. The direct and indirect effect coefficients of LGC are 0.012 and 0.038 , respectively, both of which pass the $1 \%$ significance test, indicating that when the government pursues a single economic growth to catch up with the other regions and ignores environmental protection, it will aggravate MCE of the local and neighboring areas. The direct and indirect effect coefficients of the moderator are -0.026 and -0.468 , respectively, which both pass the $10 \%$ significance test, showing that LGC not only strengthens the inhibiting effect of ER on local MCE but also weakens the promoting effect of ER on neighboring MCE. It may be that local governments tend to be "top-totop competition" in the governance of MCE with the constraints of ER. Local governments strengthen environmental performance assessment while pursuing economic development and actively promote the manufacturing green transformation ( $\mathrm{Li}$ et al. 2021a), contributing to the improvement of environmental quality. Neighboring governments strengthen regional collaborative pollution control to improve the economic quality, which produces a "favorable effect" and promote MCE reduction.

In terms of control variables, the direct effect and spatial spillover effect of PGDP are -0.097 and 0.664, respectively, both of which pass the significance test, indicating that promoting economic development significantly reduces local MCE and increases surrounding MCE, which may be because, with the development of economic intensification, local governments put more emphasis on improving economic quality. The regional economic development trend with the goal of high quality attracts the inflow of mobility factors such as technology, industry, and senior talents that prefer a high-quality environment in the surrounding areas; the siphoning effect further strengthens environmental improvement and reduces the inflow of favorable environmental elements in neighboring areas, which is unfavorable for reducing neighboring MCE.

The direct effect of OD is 0.166 and passes the $1 \%$ significance test; the indirect effect is 0.021 but insignificant, 
indicating that increasing internal openness promotes the increase of local manufacturing carbon emissions, but has no significant promotion effect on neighboring areas. It may be that further opening up in the local areas attracts more manufacturing enterprises to invest and build factories locally, leading to an increase in MCE. The direct effect of UR is 0.066 , passing $5 \%$ significance test, and the spatial spillover effect is -0.023 , failing the significance test, indicating that the increase in unemployment rate promotes local MCE and inhibits neighboring MCE, but the spillover effect is not obvious. It may be due to the reduction of regional environmental management jobs, prompting the unemployed to turn to the surrounding areas to participate in environmental governance, probably conducive to neighboring MCE reduction. The direct effect of FES is -0.540 , passing the $1 \%$ significance test, and the indirect effect is 0.012 , which does not pass the significance test, indicating that the improvement of fiscal expenditure scale has a significant inhibitory effect on local MCE, but the spillover effect is not significant. It may be that the increase in local government expenditure scale increases the investment in environmental governance, which is conducive to improving local environmental quality, but it is challenging to have a significant impact on neighboring pollution control. The direct effect and spillover effect of PFI are both 0.03 , both passing the $1 \%$ significance test, which demonstrates that increasing public facilities investment is unfavorable for the local and neighboring MCE reduction, which may be that the local government expands the construction of public resource infrastructure, causing massive energy consumption. Neighboring governments may blindly follow, resulting in the excessive supply of shared resources, a decrease in resource allocation efficiency, and aggravation in MCE.

\section{Result of the regional boundary of ER on MCE}

According to the attenuation law of geographical distance, a spatial distance attenuation weight matrix is constructed to test the attenuation boundary of the spillover effect of ER on MCE. In general, the spatial correlation gradually decreases with the increase of the distance. To further explore the attenuation boundary of the spatial spillover of ER on MCE, this study refers to Hao et al. (2020) and sets different distance thresholds; assuming that the province $j$ of distance province $i$ is outside the distance threshold, it is $1 / d_{i j}$; otherwise, it is 0 . The calculation method is as follows:

Deca $_{i j}=\left\{\begin{array}{c}\frac{1}{d_{i j}} \text { when } d_{i j} \text { is outside the distance threshold } \\ 0 \text { when } d_{i j} \text { is within the distance threshold }\end{array}\right.$

$D_{e c a_{i j}}$ reflects whether the spatial correlation coefficient decreases with the increase of the distance between spatial units. Firstly, the initial distance threshold of $d_{i j}$ is set as $200 \mathrm{~km}$ and increased by $200 \mathrm{~km}$. Secondly, SPDM is employed to examine and record the spatial spillover coefficient of ER.

The results show that the spatial spillover coefficient of ER passes the significance test of $1 \%$ within the range of
Fig. 5 Attenuation process of the spatial spillover effect of environmental regulation

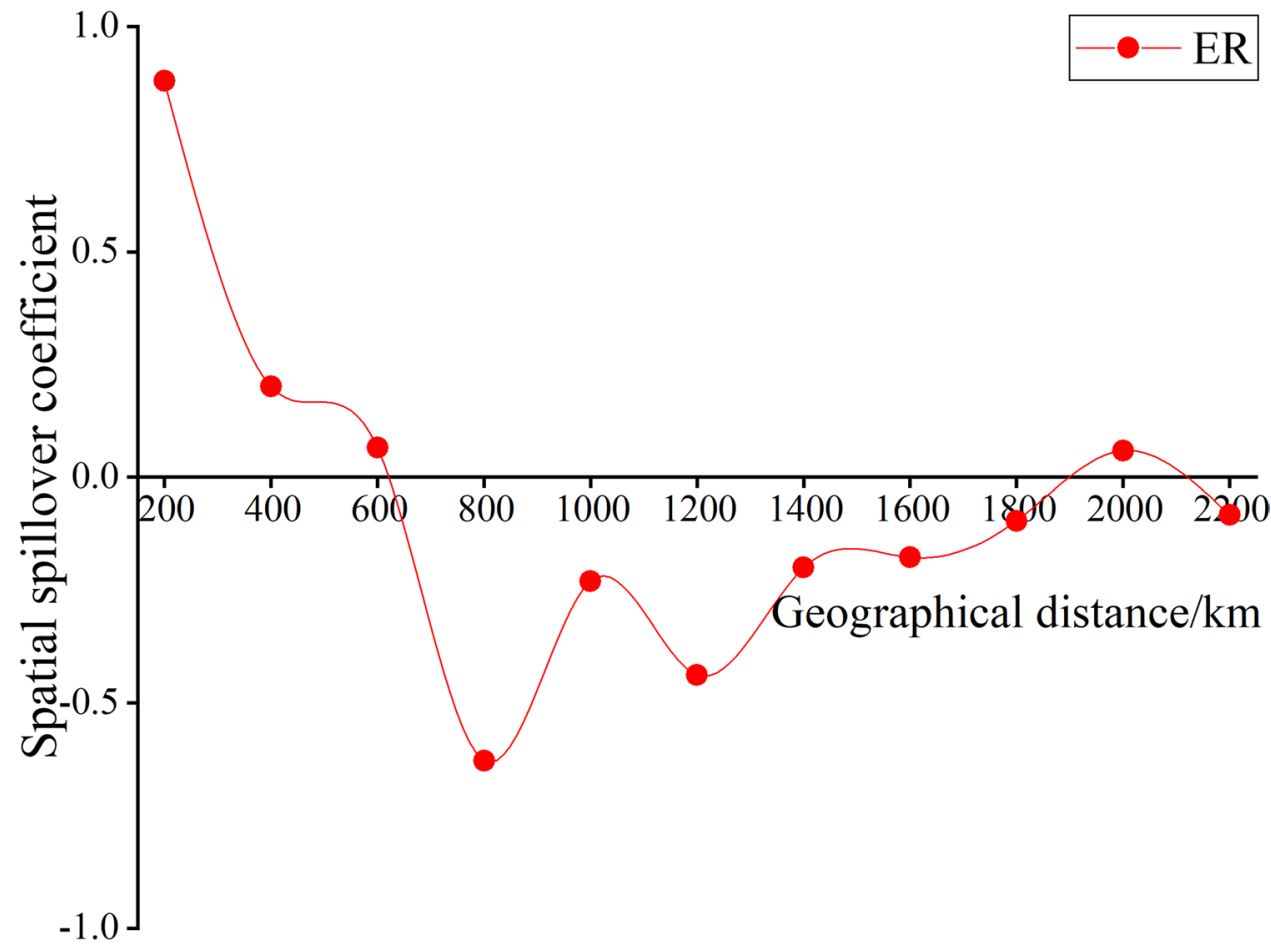


200-1600 km and is not significant after $1600 \mathrm{~km}$, which demonstrates that there is an attenuation boundary of the spatial spillover of ER on MCE. Overall, it can be roughly divided into three areas in Fig. 5: (1) Within 600 km, ER significantly promotes neighboring $\mathrm{MCE}$, and the closer the distance, the stronger the effect. The reason for the "polarization effect" may be the existence of "cooperative competition." The economic ties are closing with the closer provinces, leading to the higher dependence on environmental quality, which begins to compete after realizing economic cooperation. Subsequently, seeking its benefit maximization for profit will cost resources and environment and aggravate pollution. (2) Within $600-1600 \mathrm{~km}$, ER significantly curbs neighboring MCE. The spillover effect increases first and then decreases, reaching a peak of -0.628 at $800 \mathrm{~km}$ and the "half decline" distance of spatial spillover around $1000 \mathrm{~km}$. The coefficient decreases from -0.628 to -0.230 ; that is to say, ER more effectively promotes MCE reduction near provincial boundaries. Within $1000 \mathrm{~km}$, provinces are strongly driven by the radiation of regional environmental governance. With the increase of space distance, the cost of regional collaboration governance increases, and the emission reduction spillover effect of ER is relatively weak. (3) After $1600 \mathrm{~km}$, the spatial spillover coefficient fluctuates randomly and is not significant, revealing that the spillover effect of ER on neighboring MCE is restricted by regional boundaries. In conclusion, the spillover effect of ER on MCE decreases with the increase of geographical distance, which has the characteristics of "spatial attenuation boundary."

\section{Result of industry heterogeneity}

Due to the differences in income, development scale, energy consumption, and factor input of segmented industries, the carbon emissions of segmented industries are heterogeneous (Wang and Jiang 2019; Aslan et al. 2018). This paper is based on three classification criteria: pollution emission intensity, core operating income, and factor density ( $\mathrm{Li}$ and Cheng 2020; Huang and Du 2020); the manufacturing industry is subdivided into three groups and seven types: pollution-intensive manufacturing (PIM) and non-pollutionintensive manufacturing (NPIM) in group A, high-income manufacturing $(\mathrm{HCM})$ and low-income manufacturing (LCM) in group B, and capital-intensive manufacturing (CIM), technology-intensive manufacturing (TIM) and labor-intensive manufacturing (LIM) in group $\mathrm{C}$, which further examines spatial heterogeneity of ER and LGC on segmented MCE.

As shown in Table 6, the impact of ER and LGC on MCE has both inter-group and intra-group differences.
Table 6 Results of industry heterogeneity

\begin{tabular}{|c|c|c|c|c|c|c|c|}
\hline \multirow[t]{3}{*}{ Variables } & \multicolumn{2}{|l|}{ Group A } & \multicolumn{2}{|l|}{ Group B } & \multicolumn{3}{|l|}{ Group C } \\
\hline & (1) & (2) & (3) & (4) & (5) & (6) & (7) \\
\hline & $P I M$ & $N P I M$ & $H C M$ & $L C M$ & $C I M$ & $T I M$ & $L I M$ \\
\hline $\ln E R$ & $\begin{array}{l}-0.064^{* * *} \\
(-3.80)\end{array}$ & $\begin{array}{l}-0.041^{\text {**** }} \\
(-3.41)\end{array}$ & $\begin{array}{l}-0.051^{\text {**** }} \\
(-3.02)\end{array}$ & $\begin{array}{l}-0.127^{* * *} \\
(-8.45)\end{array}$ & $\begin{array}{l}-0.021 \\
(-1.19)\end{array}$ & $\begin{array}{l}-0.275 \\
(-0.71)\end{array}$ & $\begin{array}{l}-0.193^{\text {*** }} \\
(-10.74)\end{array}$ \\
\hline $\ln L G C$ & $\begin{array}{l}0.027^{* * *} \\
(4.49)\end{array}$ & $\begin{array}{l}-0.005 \\
(-1.18)\end{array}$ & $\begin{array}{l}0.028^{* * *} \\
(4.72)\end{array}$ & $\begin{array}{l}0.012^{* *} \\
(2.18)\end{array}$ & $\begin{array}{l}0.038^{* * *} \\
(6.17)\end{array}$ & $\begin{array}{l}0.031^{* * *} \\
(3.34)\end{array}$ & $\begin{array}{l}-0.034 \\
(-1.23)\end{array}$ \\
\hline $\ln E R \times L G C$ & $\begin{array}{l}-0.169 \\
(-1.38)\end{array}$ & $\begin{array}{l}0.095 \\
(1.07)\end{array}$ & $\begin{array}{l}-0.213 \\
(-1.04)\end{array}$ & $\begin{array}{l}-0.351 \\
(-1.22)\end{array}$ & $\begin{array}{l}-0.363 \\
(-0.85)\end{array}$ & $\begin{array}{l}-0.656 \\
(1.48)\end{array}$ & $\begin{array}{l}0.686 \\
(1.12)\end{array}$ \\
\hline Control variables & $Y E S$ & & & & & & \\
\hline$W \times \ln E R$ & $\begin{array}{l}0.505^{* * *} \\
(3.75)\end{array}$ & $\begin{array}{l}0.044 \\
(0.45)\end{array}$ & $\begin{array}{l}0.528 \\
(0.91)\end{array}$ & $\begin{array}{l}0.068 \\
(0.56)\end{array}$ & $\begin{array}{l}0.579 \\
(1.11)\end{array}$ & $\begin{array}{l}0.412 \\
(1.02)\end{array}$ & $\begin{array}{l}-0.066 \\
(-0.42)\end{array}$ \\
\hline$W \times \ln L G C$ & $\begin{array}{l}0.253^{* * *} \\
(5.77)\end{array}$ & $\begin{array}{l}0.017 \\
(0.54)\end{array}$ & $\begin{array}{l}0.254^{* * *} \\
(5.79)\end{array}$ & $\begin{array}{l}0.038^{*} \\
(1.80)\end{array}$ & $\begin{array}{l}0.305^{* * *} \\
(6.62)\end{array}$ & $\begin{array}{l}0.407^{\text {*** }} \\
(6.21)\end{array}$ & $\begin{array}{l}0.135 \\
(0.77)\end{array}$ \\
\hline$W \times \ln E R \times L G C$ & $\begin{array}{l}-3.982^{* * *} \\
(-4.91)\end{array}$ & $\begin{array}{l}-0.066 \\
(-0.12)\end{array}$ & $\begin{array}{l}-4.139^{* * *} \\
(-5.09)\end{array}$ & $\begin{array}{l}-0.526^{*} \\
(-1.74)\end{array}$ & $\begin{array}{l}-5.115^{* * *} \\
(-5.99)\end{array}$ & $\begin{array}{l}-5.246^{* * *} \\
(-4.30)\end{array}$ & $\begin{array}{l}-3.256^{\text {*** }} \\
(3.58)\end{array}$ \\
\hline Control variables & $Y E S$ & & & & & & \\
\hline Spatial rho & $\begin{array}{l}-0.825^{* * *} \\
(-3.28)\end{array}$ & $\begin{array}{l}-0.735^{* * *} \\
(-3.16)\end{array}$ & $\begin{array}{l}-0.891^{* * *} \\
(-3.54)\end{array}$ & $\begin{array}{l}-0.896^{* * *} \\
(-3.65)\end{array}$ & $\begin{array}{l}-0.702^{* * *} \\
(-2.92)\end{array}$ & $\begin{array}{l}-0.321 \\
(-1.47)\end{array}$ & $\begin{array}{l}-0.440^{* *} \\
(-2.05)\end{array}$ \\
\hline Variance sigma2_e & $\begin{array}{l}0.009^{* * * *} \\
(13.68)\end{array}$ & $\begin{array}{l}0.005^{* * *} \\
(13.75)\end{array}$ & $\begin{array}{l}0.009^{* * *} \\
(13.63)\end{array}$ & $\begin{array}{l}0.007^{* * *} \\
(13.61)\end{array}$ & $\begin{array}{l}0.009^{* * *} \\
(13.74)\end{array}$ & $\begin{array}{l}0.020^{* * * *} \\
(13.91)\end{array}$ & $\begin{array}{l}0.010^{* * * *} \\
(13.94)\end{array}$ \\
\hline$R^{2}$ & 0.425 & 0.121 & 0.402 & 0.395 & 0.244 & 0.280 & 0.207 \\
\hline$N$ & 390 & & & & & & \\
\hline
\end{tabular}

Note: $* * *$, and $* * *$ indicate significance at the $10 \%, 5 \%$, and $1 \%$ levels, respectively. The $t$ values are in parentheses 
The results of group A show that the coefficients of ER on pollution-intensive MCE and non-pollution-intensive MCE are -0.064 and -0.041 at $1 \%$ significance, respectively, indicating that compared with non-pollution-intensive manufacturing, ER can significantly inhibit pollution-intensive MCE, which means that pollution-intensive manufacturing is more susceptible to environmental regulation and thus chooses cross-regional transfer rather than technological innovation. The spatial influence coefficient of ER on pollution-intensive MCE is 0.505 , and at the $1 \%$ significance test, it shows that environmental regulation has a significant positive spillover effect. The influence coefficient and spatial interaction coefficient of LGC on pollution-intensive MCE are 0.027 and 0.253 , respectively, both of which are significant at $1 \%$ level, indicating that local government competition not only significantly promotes local pollution-intensive MCE, but also promotes the rapid development in surrounding manufacturing and aggravates environmental pollution. The spatial impact coefficient of the interaction of ER and LGC on the pollution-intensive MCE is significantly - 3.982, which shows that compared with the non-pollution-intensive manufacturing industry, LGC significantly increases pollutionintensive MCE. However, the combined effect of ER and LGC has negative impacts on pollution-intensive MCE significantly, this demonstrates that under the constraints of ER, LGC significantly restrains the spatial spillover of pollution-intensive MCE, which may be because in a single pursuit of economic growth, local governments ignore carbon emissions, but when environmental quality included local government performance assessment, the government competes "top to top" to attract the mobility elements to improve environmental quality. The surrounding areas further strengthen the experiential learning of environmental governance through the "scale effect" to reduce MCE.

In group B, the coefficients of ER on high-income and low-income MCE are -0.051 and -0.127 respectively, both of which are significant at $1 \%$ level, which means that compared with high-income manufacturing, strengthening environmental regulation more significantly inhibits lowincome MCE. One possible reason may be that low-income manufacturing industry is willing to strengthen source governance and reduce energy consumption in the production to control environmental cost, which contributes to lowering MCE. The influence coefficients of LGC on high-income CE and low-income CE are significantly 0.028 and 0.012 , respectively, indicating that local government competition significantly promotes high-income and low-income MCE and the promotion is stronger in high-income MCE. It may be for the pursuit of economic development, local governments provide preferential policies to high-income manufacturing industries and encourage enterprise economic activities more frequently, which is not helpful to MCE reduction. Meanwhile, the spatial coefficients of LGC on high-income and low-income MCE are significantly 0.254 and 0.038 , respectively, which shows that the spatial effect of LGC on high-income MCE is more positive. The spatial coefficients of the interaction of ER and LGC on high-income and lowincome MCE are -4.139 and -0.526 , respectively, and both pass the significance test, which indicates that LGC behavior tends to "top-to-top competition" after the government takes environmental quality into account, which significantly promotes MCE reduction in high-income and low-income manufacturing industries.

The results of group $\mathrm{C}$ indicate that the influence coefficient of ER on labor-intensive MCE is -0.193 and passes the $1 \%$ significance test, but no significant impact on capitalintensive and technology-intensive MCE, which may be that industry is transforming from the middle stage to the later stage in current China, and the labor force has the characteristics of "non-infinite supply." In the evolution of transforming labor-intensive industries into capital-intensive and technology-intensive industries, labor-intensive industries still dominate. At this time, strengthening ER may inhibit labor-intensive MCE. The coefficients of LGC on capitalintensive and technology-intensive MCE are significantly 0.038 and 0.031 , respectively, indicating that LGC significantly promotes their MCE. It may be the local government, to accelerate the industrial transformation and upgrading, increases support policy for capital-intensive and technology-intensive manufacturing and attracts many flow factors to develop them, thus increasing their MCE. In addition, the spatial coefficients of LGC on capital-intensive and technology-intensive MCE are 0.305 and 0.407 , respectively, both passing the $1 \%$ significance test, which indicates that LGC has a significant positive spatial spillover effect on capitalintensive and technology-intensive MCE. It may be blindly followed by local government's excessive increase in factor input, resulting in reduced resource allocation efficiency and further aggravating MCE. In addition, the spatial coefficients of the interaction between ER and LGC on laborintensive, capital-intensive, and technology-intensive MCE are $-5.115,-5.246$, and -3.256 , respectively, all passing the $1 \%$ significance test, which shows that LGC significantly reduces MCE in labor-intensive, capital-intensive, and technology-intensive manufacturing. Among them, the carbon emission reduction effect is strong in technology-intensive manufacturing industries, which may be because ER forces enterprises to innovate green technology, resulting in the promotion of energy conservation and emission reduction in manufacturing by improving the efficiency of resource allocation and reducing energy consumption.

\section{Robustness test}

In order to test the reliability of conclusions, the following methods are used to conduct a robustness test. The results 
are shown in Table 8: (1) To help to eliminate the estimation bias caused by the selection of spatial weight matrix $(\mathrm{Xu}$ et al. 2019), this study replaces the geographic distance matrix with an adjacent matrix, economic distance matrix, and economic-geographic distance nested matrix in turn for further verification. Adjacent space weight matrix refers to the adjacent relationship among the subregions (Morton et al. 2018). It can be defined as follows: $W_{i j}^{A}=\left\{\begin{array}{c}\text { 1ifprovincesiandjareadiacent } \\ \text { 0ifprovincesiandjarenotadiacent }\end{array}\right.$. The economic dis-

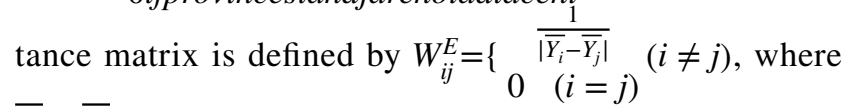
$\bar{Y}_{i}-\bar{Y}_{j}$ is the average value of per capita GDP in the provinces $i$ and $j$ from 2007 to 2019. Referring to Fingleton and Le Gallo (2008), the economic distance matrix and the geographical distance matrix are combined to construct the economic-geographic distance nested matrix as follows: $W_{i j}^{Q}=\left\{\begin{array}{l}\frac{\left|\bar{Y}_{i}-\bar{Y}_{j}\right|}{d_{i j}} \\ 0 \quad(i=j)\end{array}(i \neq j)\right.$, where $d_{i j}$ is the geospatial distance between provinces $i$ and $j$, which is evaluated by the latitude and longitude of the capital cities of provinces $i$ and $j . \bar{Y}_{i}-\bar{Y}_{j}$ is the average value of per capita GDP in the provinces $i$ and $j$ from 2007 to 2019. (2) Replace the explained variable. Use manufacturing carbon intensity (MCI) to verify again. (3) Replace explanatory variables. Some experts distinguish between command-and-control and market incentives (Zhu et al. 2021; Jiang et al. 2021; Sun et al. 2021; Wang et al. 2018a). The comprehensive index of environmental regulation measured by the removal rate of five pollutants is a proxy variable for command-and-control environmental regulation. To avoid estimation bias caused by the selection of variables, provincial emission fees are selected as the measure index of market-incentive environmental regulation to be included in the model for revalidation. The results show that the coefficients of command-andcontrol ER and market-incentive ER (Table 4, Table 8) are -0.104 and -0.81 , respectively, both significant at the $1 \%$ level, indicating that the effect of command-and-control ER on MCE reduction is stronger than that of marketincentive ER. On the one hand, China's treatment of environmental pollution follows the principle of "government-led, market-regulated," and command-andcontrol ER is the main means. On the other hand, China's carbon tax, carbon trading market, and management mechanisms are still immature, and the promotion effect of MCE reduction is weak. (4) Endogenous test. To address the potential endogenous issue, this paper adopts the explained variable lag 1 period as an instrumental variable and systematic generalized moment estimation (SYSGMM) to deal with the possible endogeneity between ER and MCE (Yuan et al. 2020). (5) Subregional test. The total sample is divided into eastern, central, and western regions for reverification. All of the above tests indicate that the results are robust.

Specifically, the subregional empirical results found that, first, the carbon emission reduction effect of ER is weak in the east and strong in the west. The coefficients of ER on MCE in the west and east are -0.141 and -0.068 at $1 \%$ significance test, respectively, demonstrating the inhibitory effect of ER on MCE in the west is stronger than that in the east, which may be that the industrial development in the east is faster and better than that in the middle and the west for a long time. The excessive accumulation of pollution emissions makes ER to be less effective in the short term. The central region with weak ER is likely to become a new "pollution sanctuary." The moderating coefficients of central and western regions are significantly -0.044 and 0.232 , respectively, illustrating that LGC significantly strengthens the effect of ER on central MCE reduction but weakens the western MCE reduction, which may be the differences in economic development between central and western regions. The western economy mainly relies on industrial-scale expansion. In contrast, in central China, to attract competitive enterprises and undertake high-quality industrial transfer, local governments give priority to improving environmental quality to attract more high-quality mobile elements. Second, in terms of spatial spillover effect, the coefficient of ER on central MCE is 0.267 and passes $1 \%$ significance test, which demonstrates that ER has a positive spillover effect on central MCE. With the industrial transformation and upgrading and transfer, the number of industries undertaken by the central region is increasing, which causes the increase of energy consumption and central MCE. In addition, the interaction terms in the middle and the west are significantly -0.222 and 0.113 , respectively, which maybe because of the differences in the economic development goals of the regional government, resulting in the heterogeneity in the carbon emission reduction effects of ER on MCE under local government competition. The above test results are in accordance with the previous ones, which verify the robustness of the model and research results.

\section{Conclusions and discussions}

Based on manufacturing panel data in 30 provinces of China from 2007 to 2019, this study first measures MCE and employs spatial autocorrelation analysis to clarify the spatial-temporal differentiation characteristics of MCE and ER. Under three different spatial weight matrices, the spatial Durbin model is employed to explore the impact mechanism, spatial spillover effect, and regional boundary of ER and LGC on MCE and further investigate the spatial heterogeneity of seven types of manufacturing. The conclusions are as follows: 
Firstly, the overall MCE shows a warp-tail shape, and the overall ER is steadily increasing. The local pattern of MCE forms a decreasing trend from east to west, and the regional differences gradually increase. Secondly, ER significantly inhibits local MCE and increases neighboring MCE. LGC significantly promotes local and neighboring MCE, which increases the carbon emission reduction effect of ER on MCE and shows a "top-to-top competition." Thirdly, there is a significant regional boundary for the spatial spillover effect of ER on MCE. ER within $600 \mathrm{~km}$ significantly promotes neighboring MCE, and the closer the distance is, the stronger the effect is. Within $600-1600 \mathrm{~km}$, ER significantly inhibits neighboring MCE, and the spillover effect first increases and then decreases, and the spatial spillover beyond $1600 \mathrm{~km}$ is not significant. Fourthly, ER significantly inhibits local pollution-intensive, low-income, and labor-intensive MCE and promotes neighboring pollutionintensive MCE. LGC weakens the MCE reduction effect of ER on neighboring high-income and technology-intensive manufacturing. Besides, the effect of ER on MCE reduction is weaker in the east and stricter in the west.

These findings suggest that not only environmental regulation but local government competition is an important way to promote emission reduction. Environmental regulation reduces the local MCE and also affects the neighboring MCE, so it is necessary to appropriately strengthen environmental regulation. However, the spatial spillover effect of ER has regional boundaries, which means that local governments should avoid blindly carrying out environmental cooperation but implement environmental governance efficiently within an effective scope. In addition, it is crucial to consider the heterogeneity of industry and regional heterogeneity to effectively control MCE, especially in pollutionintensive, low-income, and labor-intensive manufacturing, also in central and eastern regions. In the future, it is needed to continue to optimize regional industry layout, upgrade industrial structure, perfect the environmental monitoring system, and improve the government's environmental performance assessment mechanism to promote MCE reduction and manufacturing green development.

The findings have important implications for manufacturing green development. First, the results confirm that environmental regulation significantly promotes MCE reduction and the emission reduction effect of command-and-control ER is more effective than that of market-incentive ER (Table 4; Table 8). Therefore, it is important to adopt a diversified combination of environmental regulation tools to promote MCE. For example, administrative measures such as emission reduction targets should be used to constrain the production behavior of the manufacturing sector. At the same time, the development of green finance and green supply chains should be promoted, and the carbon trading market should be continuously improved to promote energy saving and emission reduction through market-incentive regulation. In addition, considering the active role of nongovernment forces in environmental governance, regulators should promote and support other social organizations to jointly participate in environmental protection, such as the monitoring role of environmental industry associations, to enhance the richness and effectiveness of environmental regulation through diversified means.

Second, the results show that local government competition enhances the promoting effect of environmental regulation on MCE reduction. Therefore, improving the performance appraisal mechanism of local governments, accelerating the transformation of government functions, and paying equal attention to rewarding incentives and punishing constraints on ecological performance are key to effectively enhancing the environmental governance capacity of local governments. For policymakers, it is necessary to consider the top-level design of tax, fiscal, and environmental policies, not only to give enterprises tax credits, pollution subsidies, and environmental incentives, but also to strengthen the punishment of environmental pollutions and to flexibly use local government to promote MCE reduction.

Third, the results support that environmental regulation has a significant spatial spillover effect and attenuation boundary on MCE reduction. Therefore, it is necessary to improve the integrated linkage mechanism, break down administrative barriers to pollution control, and establish a multilevel and multi-type collaborative governance platform by using emerging information technology means such as big data and AI to timely grasp the operating status of manufacturing enterprises in various regions and the implementation effect of environmental policies. Improving the digital and intelligent level of environmental governance, it is helpful to promote the coordinated governance of carbon emissions in cross-regional manufacturing industries.

Fourth, the results prove that environmental regulation and local government competition have industry heterogeneity on MCE reduction. The government should implement targeted and differentiated measures to promote manufacturing low-carbon transformation. For example, for pollutionintensive manufacturing, the government should strengthen prevention and control and guide the environmental treatment behavior of polluting industries by setting appropriate environmental access standards to achieve source control. For the non-pollution-intensive manufacturing, the government should enhance the ability of control in the middle of the process and guide the non-pollution-intensive manufacturing industry to carry out environmental governance through the effective combination of command-and-control and market-incentive ER to enhance the effectiveness of environmental regulation. For different factor-intensive manufacturing industries, the government should enhance the environmental supervision intensity of labor-intensive 
manufacturing industries, promote clean technology innovation, introduce advanced technology and management, and attract high-level talents, thereby promoting green transformation. For technology-intensive and capital-intensive manufacturing industries, it should strengthen the optimal combination of various environmental regulation instruments and, at the same time, give tax concessions and improve financing channels to promote the intelligent and green transformation.

Finally, the results show that environmental regulation has regional heterogeneity on MCE. Therefore, the government should take environmental measures according to regional development characteristics and environmental governance needs. For example, for the eastern provinces with more advanced economies, the focus should be on adopting market-incentive ER and giving full play to the externalities of environmental regulation through market mechanisms such as sewage charges and trading permits. At the same time, it is necessary to gather the scale advantages of the manufacturing industry, improve the efficiency of resource allocation, and play an exemplary and leading role in modernization. For the central region, it is necessary to appropriately strengthen environmental regulation and improve the financial transfer payment of local governments to optimize the layout of the manufacturing industry, undertake the eastern industry with high quality, and achieve the sustainable development in manufacturing. For the western regions, which are economically backward, in the process of accurately planning the new pattern of the western manufacturing industry and strengthening infrastructural support construction, more imperative environmental regulations should be adopted to restrict the production behavior of high-pollution industries to help achieve the goals of carbon peak and carbon neutrality.

This study provides new evidence for environmental regulation to promote manufacturing carbon emission reduction from the perspective of local government competition. Although this study takes China as an example, how manufacturing industries achieve low-carbon and green development is not only a concern in China, but is a focus of attention worldwide, especially in the post-COVID-19 era, an increasing number of countries have begun to pay attention to environmental problems in the process of economic development. The results of this study may provide empirical support for manufacturing carbon emission reduction in other developing countries, especially those with energy dependence and promptly manufacturing development. In addition, the impact of ER on MCE from the perspective of LGC is the focus of this study, but further research is needed. First of all, due to the availability, using provinciallevel data may cause sample bias, and subsequent research can be carried out at the prefecture-level cities or enterprise level. Secondly, according to the existing literature, manufacturing is subdivided by only three criteria, and future research of industry heterogeneity can be explored from more dimensions. Finally, most of the existing studies are based on Chinese data, and future studies can try to compare the impact of ER and its interaction with the government on MCE in different nations, which contributes to further identify their inherent impact and have more insight into environmental policy and local government behavior in manufacturing.

\section{Appendix}

Table 7

Table 8

Table 7 Description of the variables

\begin{tabular}{llll}
\hline Variable & Definition & Unit & Data source \\
\hline MCE & Manufacturing carbon emissions & Million tons & CEADs(2019) \\
ER & Environmental regulation & $\%$ & CESY(2020) \\
LGC & Local government competition & $\%$ & CSY $(2020)$ \\
PGDP & Per capital GDP & Yuan & CSY (2020) \\
OD & Opening degree & $\%$ & CSY $(2020)$ \\
UR & Unemployment rate & $\%$ & CSY $(2020)$ \\
FES & Fiscal expenditure scale & $\%$ & CSY $(2020)$ \\
PFI & Public facilities investment & $/ 100,000$ persons & CSY $(2020)$ \\
\hline
\end{tabular}


Table 8 Robustness test

\begin{tabular}{|c|c|c|c|c|c|c|c|c|c|}
\hline Variables & $\begin{array}{r}(1) \\
W_{i j}^{A} \\
\end{array}$ & $\begin{array}{r}(2) \\
W_{i j}^{E} \\
\end{array}$ & $\begin{array}{l}(3) \\
W_{i j}^{Q} \\
\end{array}$ & $\begin{array}{l}\text { (4) } \\
\text { MCI }\end{array}$ & $\begin{array}{l}\text { (5) } \\
\text { PW }\end{array}$ & $\begin{array}{l}(6) \\
\text { Eastern }\end{array}$ & $\begin{array}{l}(7) \\
\text { Central }\end{array}$ & $\begin{array}{l}(8) \\
\text { Western }\end{array}$ & $\begin{array}{l}\text { (9) } \\
\text { SYS-GMM }\end{array}$ \\
\hline $\ln E R$ & $\begin{array}{l}-0.104^{* * *} \\
(-6.36)\end{array}$ & $\begin{array}{l}-0.014^{*} \\
(-1.76)\end{array}$ & $\begin{array}{l}-0.058^{* * *} \\
(-3.66)\end{array}$ & $\begin{array}{l}-0.153^{* * *} \\
(-3.93)\end{array}$ & $\begin{array}{l}-0.081^{* * *} \\
(-10.89)\end{array}$ & $\begin{array}{l}-0.068^{* * * *} \\
(-2.85)\end{array}$ & $\begin{array}{l}-0.032 \\
(-0.76)\end{array}$ & $\begin{array}{l}-0.141^{* * *} \\
(-4.14)\end{array}$ & $\begin{array}{l}-0.014^{*} \\
(-1.69)\end{array}$ \\
\hline $\ln L G C$ & $\begin{array}{l}0.011^{* *} \\
(2.04)\end{array}$ & $\begin{array}{l}0.023^{\text {**** }} \\
(4.45)\end{array}$ & $\begin{array}{l}0.027^{* * * *} \\
(4.89)\end{array}$ & $\begin{array}{l}0.106^{* * *} \\
(7.67)\end{array}$ & $\begin{array}{l}0.025^{\text {*** }} \\
(5.36)\end{array}$ & $\begin{array}{l}0.022 \\
(0.65)\end{array}$ & $\begin{array}{l}0.005^{*} \\
(1.76)\end{array}$ & $\begin{array}{l}-0.004^{*} \\
(-1.70)\end{array}$ & $\begin{array}{l}0.008^{* * *} \\
(2.63)\end{array}$ \\
\hline $\ln E R \times L G C$ & $\begin{array}{l}-0.038^{*} \\
(-1.73)\end{array}$ & $\begin{array}{l}-0.279^{* *} \\
(-2.34)\end{array}$ & $\begin{array}{l}-0.198^{*} \\
(-1.71)\end{array}$ & $\begin{array}{l}-1.627^{* * *} \\
(-5.73)\end{array}$ & $\begin{array}{l}-0.269^{* * *} \\
(-3.46)\end{array}$ & $\begin{array}{l}-0.003 \\
(-0.02)\end{array}$ & $\begin{array}{l}-0.044^{*} \\
(-1.83)\end{array}$ & $\begin{array}{l}0.232^{* * *} \\
(3.20)\end{array}$ & $\begin{array}{l}-0.139^{*} \\
(-1.66)\end{array}$ \\
\hline L.InMCE & & & & & & & & & $\begin{array}{l}0.732^{* * *} \\
(23.02)\end{array}$ \\
\hline Control variables & YES & & & & & & & & \\
\hline$W \times \ln E R$ & $\begin{array}{l}0.009^{*} \\
(1.68)\end{array}$ & $\begin{array}{l}0.213^{\text {**** }} \\
(3.79)\end{array}$ & $\begin{array}{l}0.158^{* * *} \\
(3.25)\end{array}$ & $\begin{array}{l}0.727^{* *} \\
(2.24)\end{array}$ & $\begin{array}{l}0.153^{* * *} \\
(2.65)\end{array}$ & $\begin{array}{l}0.541 \\
(0.85)\end{array}$ & $\begin{array}{l}0.267^{* * *} \\
(2.88)\end{array}$ & $\begin{array}{l}0.343 \\
(0.27)\end{array}$ & $\begin{array}{l}\text { Sargan } \\
20.570\end{array}$ \\
\hline$W \times \ln L G C$ & $\begin{array}{l}0.031^{* * *} \\
(3.19)\end{array}$ & $\begin{array}{l}0.034^{* *} \\
(2.00)\end{array}$ & $\begin{array}{l}0.082^{* * *} \\
(4.80)\end{array}$ & $\begin{array}{l}0.548^{* * *} \\
(5.37)\end{array}$ & $\begin{array}{l}0.067^{*} \\
(1.78)\end{array}$ & $\begin{array}{l}0.288^{\text {**** }} \\
(4.69)\end{array}$ & $\begin{array}{l}0.058^{*} \\
(1.96)\end{array}$ & $\begin{array}{l}-0.044 \\
(-0.72)\end{array}$ & $\begin{array}{l}(1.000) \\
A R(1)\end{array}$ \\
\hline$W \times \ln E R \times L G C$ & $\begin{array}{l}-0.394^{*} \\
(-1.84)\end{array}$ & $\begin{array}{l}-0.422 \\
(-1.12)\end{array}$ & $\begin{array}{l}-0.917^{* * *} \\
(-2.63)\end{array}$ & $\begin{array}{l}-9.056^{* * *} \\
(-4.73)\end{array}$ & $\begin{array}{l}-0.251 \\
(-0.45)\end{array}$ & $\begin{array}{l}-4.845 \\
(-1.24)\end{array}$ & $\begin{array}{l}-0.222^{* *} \\
(-2.41)\end{array}$ & $\begin{array}{l}0.113^{*} \\
(1.84)\end{array}$ & $\begin{array}{l}-2.58 \\
(0.010)\end{array}$ \\
\hline$W \times$ Control variables & $Y E S$ & & & & & & & & \\
\hline Spatial rho & $\begin{array}{l}0.154^{* *} \\
(2.16)\end{array}$ & $\begin{array}{l}0.170^{*} \\
(1.68)\end{array}$ & $\begin{array}{l}0.184^{*} \\
(1.69)\end{array}$ & $\begin{array}{l}0.059^{*} \\
(1.74)\end{array}$ & $\begin{array}{l}1.009^{* * *} \\
(4.00)\end{array}$ & $\begin{array}{l}-0.039 \\
(-0.45)\end{array}$ & $\begin{array}{l}0.156^{*} \\
(1.72)\end{array}$ & $\begin{array}{l}0.296^{* * *} \\
(3.93)\end{array}$ & $\begin{array}{l}A R(2) \\
-0.53\end{array}$ \\
\hline Variance sigma2_e & $\begin{array}{l}0.010^{* * *} \\
(13.89)\end{array}$ & $\begin{array}{l}0.009^{* * *} \\
(13.90)\end{array}$ & $\begin{array}{l}0.009^{* * *} \\
(14.88)\end{array}$ & $\begin{array}{l}0.047^{* * *} \\
(13.96)\end{array}$ & $\begin{array}{l}0.007^{* * *} \\
(13.51)\end{array}$ & $\begin{array}{l}0.012^{* * *} \\
(12.85)\end{array}$ & $\begin{array}{l}0.006^{* * *} \\
(12.79)\end{array}$ & $\begin{array}{l}0.003^{* * *} \\
(12.69)\end{array}$ & $(0.596)$ \\
\hline$N$ & 390 & 390 & 390 & 390 & 390 & 143 & 104 & 143 & 360 \\
\hline
\end{tabular}

Note: $* * *$, and $* * *$ indicate significance at the $10 \%, 5 \%$, and $1 \%$ levels, respectively. The $t$ values are in parentheses

Author contribution Chanyuan Liu (first author): conceptualization, formal analysis, data curation, methodology, and writing —original draft. Long Xin (corresponding author): formal analysis, software, validation, visualization, and writing — original draft. Jinye Li (corresponding author): supervision, project administration, writing — review and editing, and funding acquisition.

Funding This research was supported by the National Natural Science Foundation of China (71964032), Xinjiang Social Science Foundation of China (19BJL028), Xinjiang Natural Science Foundation of China (2018D01C052), and Autonomous Region Graduate Research Innovation Project of China (XJ2019G004).

Data availability The data is available when the reader asks for it.

\section{Declarations}

Ethics approval The work does not involve any hazards, such as the use of animal or human subjects' issue.

Competing interests The authors declare no competing interests.

\section{References}

Abokyi E, Appiah-Konadu P, Tangato KF, Abokyi F (2021) Electricity consumption and carbon dioxide emissions: the role of trade openness and manufacturing sub-sector output in Ghana. Energy
Clim Change 2:100026. https://doi.org/10.1016/j.egycc.2021. 100026

Acheampong AO, Adams S, Boateng E (2019) Do globalization and renewable energy contribute to carbon emissions mitigation in Sub-Saharan Africa? Sci Total Environ 677:436-446. https://doi. org/10.1016/j.scitotenv.2019.04.353

Alam MM, Murad MW (2020) The impacts of economic growth, trade openness and technological progress on renewable energy use in organization for economic co-operation and development countries. Renew Energ 145:382-390. https://doi.org/10.1016/j. renene.2019.06.054

Albornoz F, Cole MA, Elliott RJ, Ercolani MG (2009) In search of environmental spillovers. World Econ 32(1):136-163. https://doi. org/10.1111/j.1467-9701.2009.01160.x

Anselin L (1989) Spatial econometrics: methods and models. Econ Georg 65(2):160-162. https://doi.org/10.2307/143780

Anser MK, Ahmad M, Khan MA et al (2021) The role of information and communication technologies in mitigating carbon emissions: evidence from panel quantile regression. Environ Sci Pollut Res 28:21065-21084. https://doi.org/10.1007/s11356-020-12114-y

Aslan A, Destek MA, Okumus I (2018) Sectoral carbon emissions and economic growth in the US: further evidence from rolling window estimation method. J Clean Prod 200:402-411. https:// doi.org/10.1016/j.jclepro.2018.07.237

Baloch A, Shah SZ, Habibullah MS et al (2021) Towards connecting carbon emissions with asymmetric changes in economic growth: evidence from linear and nonlinear ARDL approaches. Environ Sci Pollut Res 28:15320-15338. https://doi.org/10.1007/ s11356-020-11672-5 
Balsalobre-Lorente D, Gokmenoglu KK, Taspinar N, Cantos-Cantos JM (2019) An approach to the pollution haven and pollution halo hypotheses in MINT countries. Environ Sci Pollut Res 26(22):23010-23026. https://doi.org/10.1007/s11356-019-05446-x

Banerjee A, Duflo E, Qian N (2020) On the road: access to transportation infrastructure and economic growth in China. J Dev Econ 145:102442. https://doi.org/10.1016/j.jdeveco.2020.102442

Banzhaf HS, Chupp BA (2012) Fiscal federalism and interjurisdictional externalities: new results and an application to US air pollution. J Public Econ 96(5-6):449-464. https://doi.org/10.1016/j.jpubeco.2012.01.001

Breton A (1998) Competitive governments: an economic theory of politics and public finance. Cambridge University Press

Cairns RD (2014) The green paradox of the economics of exhaustible resources. Energy Pol 65:78-85. https://doi.org/10.1016/j.enpol. 2013.10.047

Chen J, Lian X, Su H et al (2021) Analysis of China's carbon emission driving factors based on the perspective of eight major economic regions. Environ Sci Pollut Res 28:8181-8204. https://doi.org/ 10.1007/s11356-020-11044-Z

Chen X, Shuai S, Tian Z, Zhen X, Peng Y (2016) Impacts of air pollution and its spatial spillover effect on public health based on China's big data sample. J Clean Prod 142:915-925. https://doi. org/10.1016/j.jclepro.2016.02.119

Chen X, Chen YE, Chang CP (2019) The effects of environmental regulation and industrial structure on carbon dioxide emission: a non-linear investigation. Environ Sci Pollut Res 26:3025230267. https://doi.org/10.1007/s11356-019-06150-6

Cheng Y, Awan U, Ahmad S, Tan Z (2021) How do technological innovation and fiscal decentralization affect the environment? A story of the fourth industrial revolution and sustainable growth. Technol Forecast Soc 162:120398. https://doi.org/10.1016/j.techf ore.2020.120398

Chen YJ, Li P, Lu Y (2018) Career concerns and multitasking local bureaucrats: evidence of a target-based performance evaluation system in China. J Dev Econ 133:84-101. https://doi.org/10. 1016/j.jdeveco.2018.02.001

Cheng Z (2016) The spatial correlation and interaction between manufacturing agglomeration and environmental pollution. Ecol Indic 61:1024-1032. https://doi.org/10.1016/j.ecolind.2015.10.060

Cheng Z, Li L, Liu J (2017) The emissions reduction effect and technical progress effect of environmental regulation policy tools. J Clean Prod 149:191-205. https://doi.org/10.1016/j.jclepro.2017.02.105

Chontanawat J (2020) Relationship between energy consumption, $\mathrm{CO} 2$ emission and economic growth in ASEAN: cointegration and causality model. Energy Rep 6:660-665. https://doi.org/10. 1016/j.egyr.2019.09.046

Cole MA, Elliott RJ, Fredriksson PG (2006) Endogenous pollution havens: does FDI influence environmental regulations? Scand J Econ 108(1):157-178. https://doi.org/10.1111/j.1467-9442. 2006.00439.x

Cole MA, Elliott RJR, Strobl E (2008) The environmental performance of firms: the role of foreign ownership, training, and experience. Ecol Econ 65(3):538-546. https://doi.org/10.1016/j.ecolecon.2007.07.025

Dong F, Li X, Long R, Liu X (2013) Regional carbon emission performance in China according to a stochastic frontier model. Renew Sustain Energy Rev 28:525-530. https://doi.org/10.1016/j.rser. 2013.08.009

Dou Y, Zhao J, Dong X, Dong K (2021) Quantifying the impacts of energy inequality on carbon emissions in China: a householdlevel analysis. Energ Econ 102:105502. https://doi.org/10.1016/j. eneco.2021.105502

Driessen PP, Dieperink C, Van Laerhoven F, Runhaar HA, Vermeulen WJ (2012) Towards a conceptual framework for the study of shifts in modes of environmental governance-experiences from the Netherlands. Environ Policy and Gov 22(3):143-160. https:// doi.org/10.1016/j.eneco.2021.105502
Du W, Li M (2020) Assessing the impact of environmental regulation on pollution abatement and collaborative emissions reduction: micro-evidence from Chinese industrial enterprises. Environ Impact Asses Rev 82:106382. https://doi.org/10.1016/j.eiar. 2020.106382

Feng T, Du H, Lin Z, Zuo J (2020) Spatial spillover effects of environmental regulations on air pollution: evidence from urban agglomerations in China. J Environ Manage 272:110998. https://doi.org/ 10.1016/j.jenvman.2020.110998

Fernando Y, Hor WL (2017) Impacts of energy management practices on energy efficiency and carbon emissions reduction: a survey of Malaysian manufacturing firms. Resour Conserv Recy 126:6273. https://doi.org/10.1016/j.resconrec.2017.07.023

Fingleton B, Le Gallo J (2008) Estimating spatial models with endogenous variables, a spatial lag and spatially dependent disturbances: finite sample properties. Pap Reg Sci 87(3):319-339. https://doi. org/10.1111/j.1435-5957.2008.00187.x

Garg P, Gupta B, Dzever S, Sivarajah U, Kumar V (2020) Examining the relationship between social media analytics practices and business performance in the Indian retail and IT industries: the mediation role of customer engagement. Int J Inf Manag 52:102069

Ge T, Li J (2020) The effect of environmental regulation intensity deviation on China's inclusive growth. Environ Sci Pollut Res 27:34158-34171. https://doi.org/10.1007/ s11356-020-09574-7

Ge T, Qiu W, Li J, Hao X (2020) The impact of environmental regulation efficiency loss on inclusive growth: evidence from China. J Environ Manag 268:110700

Geniaux G, Martinetti D (2018) A new method for dealing simultaneously with spatial autocorrelation and spatial heterogeneity in regression models. Reg Sci Urban Econ 72:74-85. https://doi. org/10.1016/j.regsciurbeco.2017.04.001

Guo W, Chen Y (2018) Assessing the efficiency of China's environmental regulation on carbon emissions based on Tapio decoupling models and GMM models. Energy Rep 4:713-723. https:// doi.org/10.1016/j.egyr.2018.10.007

Han Y (2020) Impact of environmental regulation policy on environmental regulation level: a quasi-natural experiment based on carbon emission trading pilot. Environ Sci Pollut Res 27:2360223615. https://doi.org/10.1007/s11356-020-08658-8

Hao Y, Gai Z, Wu H (2020) How do resource misallocation and government corruption affect green total factor energy efficiency? Evidence from China. Energy Policy 143:111562. https://doi.org/ 10.1016/j.enpol.2020.111562

Haseeb M, Haouas I, Nasih M, Mihardjo LW, Jermsittiparsert K (2020) Asymmetric impact of textile and clothing manufacturing on carbon-dioxide emissions: evidence from top Asian economies. Energy 196:117094. https://doi.org/10.1016/j.energy.2020. 117094

Hashmi R, Alam K (2019) Dynamic relationship among environmental regulation, innovation, $\mathrm{CO} 2$ emissions, population, and economic growth in OECD countries: a panel investigation. $\mathbf{J}$ Clean Prod 231:1100-1109. https://doi.org/10.1016/j.jclepro. 2019.05.325

Hong Y, Lyu X, Chen Y, Li W (2020) Industrial agglomeration externalities, local governments' competition and environmental pollution: evidence from Chinese prefecture-level cities. J Clean Prod 277:123455. https://doi.org/10.1016/j.jclep ro. 2020.123455

Huang Z, Du X (2020) Toward green development? Impact of the carbon emissions trading system on local governments' land supply in energy-intensive industries in China. Sci Total Environ 738:139769. https://doi.org/10.1016/j.scitotenv.2020.139769

HÜBler M, Keller A (2010) Energy savings via FDI? Empirical evidence from developing countries. Environ Dev Econ 15(1):5980. https://doi.org/10.1017/S1355770X09990088 
IPCC (2007) Climate change 2007: the fourth assessment report of the intergovernmental panel on climate change. Cambridge University Press, England. https://www.ipcc.ch/report/ar4/syr/

Jiang Z, Wang Z, Lan X (2021) How environmental regulations affect corporate innovation? The coupling mechanism of mandatory rules and voluntary management. Technol Soc 65:101575. https://doi.org/10.1016/j.techsoc.2021.101575

Jin H, Qian Y, Weigngast BR (2005) Regional decentralization and fiscal incentives: federalism, Chinese style. J Publ Econ 89:17191742. https://doi.org/10.1016/j.jpubeco.2004.11.008

Khan Z, Ali S, Dong K, Li RYM (2021) How does fiscal decentralization affect $\mathrm{CO}_{2}$ emissions? The roles of institutions and human capital. Energy Econ 94:105060. https://doi.org/10.1016/j.eneco. 2020.105060

Konisky DM (2007) Regulatory competition and environmental enforcement: is there a race to the bottom? Am J Polit Sci 51(4):853-872. https://doi.org/10.1111/j.1540-5907.2007. 00285.x

Kunce M, Shogren JF (2005) On interjurisdictional competition and environmental federalism. J Environ Econ Manag 50(1):212224. https://doi.org/10.1016/j.jeem.2004.11.004

Lai YB (2019) Environmental policy competition and heterogeneous capital endowments. Reg Sci Urban Econ 75:107-119. https:// doi.org/10.1016/j.regsciurbeco.2019.01.011

Lee JY, Choi S (2021) Supply chain investment and contracting for carbon emissions reduction: a social planner's perspective. Internal J Prod Econ 231:107873. https://doi.org/10.1016/j.jpe.2020.107873

LeSage J, Pace RK (2009) Introduction to spatial econometrics. CRC Press, Boca Raton. https://doi.org/10.1201/9781420064254

Levinson A (2003) Environmental regulatory competition: a status report and some new evidence. Nati Tax J 56(1):91-106. https:// doi.org/10.17310/ntj.2003.1.06

Li G, Wei W (2021) Financial development, openness, innovation, carbon emissions, and economic growth in China. Energy Econ 97:105194. https://doi.org/10.1016/j.eneco.2021.105194

Li HL, Zhu XH, Chen JY, Jiang FT (2019) Environmental regulations, environmental governance efficiency and the green transformation of China's iron and steel enterprises. Ecol Econ 165:106397. https://doi.org/10.1016/j.ecolecon.2019.106397

Li J, Cheng Z (2020) Study on total-factor carbon emission efficiency of China's manufacturing industry when considering technology heterogeneity. J Clean Prod 260:121021. https://doi.org/10. 1016/j.jclepro.2020.121021

Li J, Lin B (2017a) Ecological total-factor energy efficiency of China's heavy and light industries: which performs better? Renew Sust Energ Rev 72:83-94. https://doi.org/10.1016/j.rser.2017.01.044

Li K, Lin B (2017b) Economic growth model, structural transformation, and green productivity in China. Appl Energ 187:489-500. https://doi.org/10.1016/j.apenergy.2016.11.075

Li L, Zhu B, Che X, Sun H, Tan M (2021a) Examining effect of green transformational leadership and environmental regulation through emission reduction policy on energy-intensive industry's employee turnover intention in China. Sustainability 13(12):6530. https://doi.org/10.3390/su13126530

Li M, Du W, Tang S (2021b) Assessing the impact of environmental regulation and environmental co-governance on pollution transfer: micro-evidence from China. Environ Impact Asses Rev 86:106467. https://doi.org/10.1016/j.eiar.2020.106467

Li S, Chu S, Shen C (2014) Local government competition, environmental regulation and regional ecological efficiency. J World Econ 37(04):88-110 (in Chinese)

Lin B, Chen G (2018) Energy efficiency and conservation in China's manufacturing industry. J Clean Prod 174:492-501. https://doi. org/10.1016/j.jclepro.2017.10.286

Lin B, Chen Y (2020) Will land transport infrastructure affect the energy and carbon dioxide emissions performance of China's manufacturing industry? Appl Energ 260:114266. https://doi.org/ 10.1016/j.apenergy.2019.114266

Liu SJ, Xu XL (2021) The pollution halo effect of technology spillover and pollution haven effect of economic growth in agricultural foreign trade: two sides of the same coin? Environ Sci Pollut Res 28(16):20157-20173. https://doi.org/10.1007/ s11356-020-11786-w

Lu Y, Wang Y, Zhang W et al (2019) Provincial air pollution responsibility and environmental tax of China based on interregional linkage indicators. J Clean Prod 235:337-347. https://doi.org/10. 1016/j.jclepro.2019.06.293

Luo NS, Jiang YQ (2017) Influences on environment pollution by local government competition and the opening up policy: taking 270 Chinese cities for example. Urban Prob 12:46-55 (in Chinese)

Ma Y, Ji Q, Fan Y (2016) Spatial linkage analysis of the impact of regional economic activities on PM2.5 pollution in China. J Clean Prod 139:1157-1167. https://doi.org/10.1016/j.jclepro. 2016.08.152

Maskin E, Qian Y, Xu C (2000) Incentives, information, and organizational form. Rev Econ Stud 67(2):359-378. https://doi.org/10. 1111/1467-937X.00135

Mert M, Caglar AE (2020) Testing pollution haven and pollution halo hypotheses for Turkey: a new perspective. Environ Sci Pollut Res 27(26):32933-32943. https://doi.org/10.1007/ s11356-020-09469-7

Milani S (2017) The impact of environmental policy stringency on industrial R\&D conditional on pollution intensity and relocation costs. Environ Resour Econ 68(3):595-620. https://doi.org/10. 1007/s10640-016-0034-2

Millimet DL (2003) Assessing the empirical impact of environmental federalism. J Reg Sci 43(4):711-733. https://doi.org/10.1111/j. 0022-4146.2003.00317.x

Morton C, Anable J, Yeboah G, Cottrill C (2018) The spatial pattern of demand in the early market for electric vehicles: evidence from the United Kingdom. J Transp Geogr 72:119-130. https://doi. org/10.1016/j.jtrangeo.2018.08.020

NBS (2020) China statistical yearbook 2020. China Statistical Press

Oates WE (2001) A reconsideration of environmental federalism. Resources for the Future Press, Washington. https://doi.org/10. 22004/ag.econ. 10460

Oates WE, Schwab RM (1988) Economic competition among jurisdictions: efficiency enhancing or distortion inducing? J Public Econ 35(3):333-354. https://doi.org/10.1016/0047-2727(88)90036-9

Ouyang X, Shao Q, Zhu X, He Q, Xiang C, Wei G (2019) Environmental regulation, economic growth and air pollution: panel threshold analysis for OECD countries. Sci Total Environ 657:234241. https://doi.org/10.1016/j.scitotenv.2018.12.056

Pei Y, Zhu Y, Liu S, Wang X, Cao J (2019) Environmental regulation and carbon emission: the mediation effect of technical efficiency. J Clean Prod 236:117599. https://doi.org/10.1016/j.jclepro.2019.07.074

Peng X (2020) Strategic interaction of environmental regulation and green productivity growth in China: green innovation or pollution refuge? Sci Total Environ 732:139200. https://doi.org/10. 1016/j.scitotenv.2020.139200

Porter ME, Van der Linde C (1995) Toward a new conception of the environment-competitiveness relationship. J Econ Perspect 9(4):97-118. https://doi.org/10.1257/jep.9.4.97

$\mathrm{Pu}$ Z, Fu J (2018) Economic growth, environmental sustainability and China mayors' promotion. J Clean Prod 172:454-465. https:// doi.org/10.1016/j.jclepro.2017.10.162

Ribeiro FDM, Kruglianskas I (2015) Principles of environmental regulatory quality: a synthesis from literature review. J Clean Prod 96:58-76. https://doi.org/10.1016/j.jclepro.2014.03.047

Ritter H, Schopf M (2014) Unilateral climate policy: harmful or even disastrous? Environ Resour Econ 58(1):155-178. https://doi.org/ 10.1007/S10640-013-9697-0 
Ryan E (2017) Negotiating environmental federalism: dynamic federalism as a strategy for good governance. Wis L Rev Forward 17

Saint Akadiri S, Alola AA, Olasehinde-Williams G, Etokakpan MU (2020) The role of electricity consumption, globalization and economic growth in carbon dioxide emissions and its implications for environmental sustainability targets. Sci Total Environ 708:134653. https://doi.org/10.1016/j.scitotenv.2019.134653

Samreen I, Majeed MT (2020) Spatial econometric model of the spillover effects of financial development on carbon emissions: a global analysis. Pak J Commer Soc Sci 14(2):569-202

Shahnazi R, Shabani ZD (2021) The effects of renewable energy, spatial spillover of $\mathrm{CO} 2$ emissions and economic freedom on $\mathrm{CO} 2$ emissions in the EU. Renew Energ 169:293-307. https://doi.org/ 10.1016/j.renene.2021.01.016

Sigman H (2005) Transboundary spillovers and decentralization of environmental policies. J Environ Econ Manag 50(1):82-101. https://doi.org/10.1016/j.jeem.2004.10.001

Sinn HW (2008) Public policies against global warming: a supply side approach. Int Tax Public Finan 15(4):360-394. https://doi.org/ 10.1007/s10797-008-9082-z

Sjöberg E, Xu J (2018) An empirical study of US environmental federalism: RCRA enforcement from 1998 to 2011. Ecol Econ 147:253-263. https://doi.org/10.1016/j.ecolecon.2018.01.024

Smulders S, Tsur Y, Zemel A (2012) Announcing climate policy: can a green paradox arise without scarcity? J Environ Econ Manag 64(3):364-376. https://doi.org/10.1016/j.jeem.2012.02.007

Sun C, Yang Y, Zhao L (2015) Economic spillover effects in the Bohai Rim Region of China: is the economic growth of coastal counties beneficial for the whole area? China Econ Rev 33:123-136. https://doi.org/10.1016/j.chieco.2015.01.008

Sun W, Yang Q, Ni Q, Kim Y (2019) The impact of environmental regulation on employment: an empirical study of China's Two Control Zone policy. Environ Sci Pollut Res 26:26472-26487. https://doi.org/10.1007/s11356-019-05840-5

Sun Z, Wang X, Liang C, Cao F, Wang L (2021) The impact of heterogeneous environmental regulation on innovation of high-tech enterprises in China: mediating and interaction effect. Environ Sci Pollut Res 28(7):8323-8336. https://doi.org/10.1007/ s11356-020-11225-w

Tiebout CM (1956) A pure theory of local expenditures. J Polit Econ 64(5):416-424. https://doi.org/10.1086/257839

Ulucak R, Khan SUD, Baloch MA, Li N (2020) Mitigation pathways toward sustainable development: is there any trade-off between environmental regulation and carbon emissions reduction? Sustain Dev 28(4):813-822. https://doi.org/10.1002/sd.2032

Van der Ploeg F, Withagen C (2012) Is there really a green paradox? J Environ Econ Manag 64(3):342-363. https://doi.org/10.1016/j. jeem.2012.08.002

Van Laerhoven F, Barnes C (2014) Communities and commons: the role of community development support in sustaining the commons. Community Dev J 49(1):118-132

Vogel D (2009) Trading up: consumer and environmental regulation in a global economy. Harvard University Press, Cambridge

Wang N, Zhu Y, Yang T (2020) The impact of transportation infrastructure and industrial agglomeration on energy efficiency: evidence from China's industrial sectors. J Clean Prod 244:118708. https:// doi.org/10.1016/j.jclepro.2019.118708

Wang Q, Jiang R (2019) Is China's economic growth decoupled from carbon emissions? J Clean Prod 225:1194-1208. https://doi.org/ 10.1016/j.jclepro.2019.03.301

Wang T, Peng J, Wu L (2021) Heterogeneous effects of environmental regulation on air pollution: evidence from China's prefecturelevel cities. Environ Sci Pollut Res 28(20):25782-25797. https:// doi.org/10.1007/s11356-021-12434-7

Wang Y, Liu H, Mao G, Zuo J, Ma J (2017) Inter-regional and sectoral linkage analysis of air pollution in Beijing-Tianjin-Hebei urban agglomeration of China. J Clean Prod 165:1436-1444. https:// doi.org/10.1016/j.jclepro.2017.07.210

Wang Y, Yan W, Ma D, Zhang C (2018a) Carbon emissions and optimal scale of China's manufacturing agglomeration under heterogeneous environmental regulation. J Clean Prod 176:140-150. https://doi.org/10.1016/j.jclepro.2017.12.118

Wang YN, Zuo YH, Chen W, Wang BW (2018b) Threshold effect and regional differences of environmental regulation on carbon emission. Res Environ Sci 31(04):601-608. https://doi.org/10. 13198/j.issn.1001-6929.2017.03.92 (in Chinese)

Wang YC (2015) Research on environmental regulation competition of China based on spatial panel model. Manag Rev 27(8):23 (in Chinese)

Wang Z, Zhu Y (2020) Do energy technology innovations contribute to $\mathrm{CO} 2$ emissions abatement? A spatial perspective. Sci Total Environ 726:138574. https://doi.org/10.1016/j.scitotenv.2020.138574

Wolde-Rufael Y, Mulat-Weldemeskel E (2021) Do environmental taxes and environmental stringency policies reduce $\mathrm{CO} 2$ emissions? Evidence from 7 emerging economies. Environ Sci Pollut Res 28:22392-22408. https://doi.org/10.1007/s11356-020-11475-8

Woods ND (2006) Interstate competition and environmental regulation: a test of the race-to-the-bottom thesis. Soc Sci Q 87(1):174-189. https://doi.org/10.1111/j.0038-4941.2006.00375.x

Wu H, Li Y, Hao Y, Ren S, Zhang P (2020) Environmental decentralization, local government competition, and regional green development: evidence from China. Sci Total Environ 708:135085. https://doi.org/10.1016/j.scitotenv.2019.135085

Xin L, Sun H, Wang H, Xiao H (2020) Research on the spatial-temporal differentiation and driving force of green economic efficiency based on the geographic detector model. J Popul Resour Environ 30(09):128-138 (in Chinese)

Xiong W (2018) The mandarin model of growth. NBER Working Paper

Xu X, Wang Z, Zhou B (2019) The empirical analysis of knowledge spillover effect measurement. Knowl Man Res Pract 17(1):83-95

Yang CH, Tseng YH, Chen CP (2012) Environmental regulations, induced $\mathrm{R} \& \mathrm{D}$, and productivity: evidence from Taiwan's manufacturing industries. Resour Energy Econ 34(4):514-532. https:// doi.org/10.1016/j.reseneeco.2012.05.001

Yang T, Liao H, Wei YM (2020) Local government competition on setting emission reduction goals. Sci Total Environ 745:141002. https://doi.org/10.1016/j.scitotenv.2020.141002

Yuan H, Feng Y, Lee CC, Cen Y (2020) How does manufacturing agglomeration affect green economic efficiency? Energy Econ 92:104944. https://doi.org/10.1016/j.eneco.2020.104944

Zeng DZ, Zhao L (2009) Pollution havens and industrial agglomeration. J Environ Econ Manag 58(2):141-153. https://doi.org/10. 1016/j.jeem.2008.09.003

Zhai X, An Y (2020) Analyzing influencing factors of green transformation in China's manufacturing industry under environmental regulation: a structural equation model. J Clean Prod 251:119760. https://doi.org/10.1016/j.jclepro.2019.119760

Zhang F, Deng X, Phillips F, Fang C, Wang C (2020) Impacts of industrial structure and technical progress on carbon emission intensity: evidence from 281 cities in China. Technol Forecast Soc Change 154:119949. https://doi.org/10.1016/j.techfore.2020.119949

Zhang H, Wei XP (2014) Green paradox or forced emission-reduction: dual effect of environmental regulation on carbon emissions. $\mathbf{J}$ Popul Resour Environ 24:21-29. https://doi.org/10.4236/tel. 2017.75073 (in Chinese)

Zhang K, Zhang ZY, Liang QM (2017) An empirical analysis of the green paradox in China: from the perspective of fiscal decentralization. Energy Policy 103:203-211. https://doi.org/10.1016/j. enpol.2017.01.023

Zhao X, Burnett JW, Fletcher JJ (2014) Spatial analysis of China province-level CO2 emission intensity. Renew Sust Energ Rev 33:1-10. https://doi.org/10.1016/j.rser.2014.01.060 
Zhao X, Yin H, Zhao Y (2015) Impact of environmental regulations on the efficiency and $\mathrm{CO}_{2}$ emissions of power plants in China. Appl Energ 149:238-247. https://doi.org/10.1016/j.apenergy. 2015.03.112

Zheng Y (2007) De facto federalism in China: reforms and dynamics of central-local relations. World Scientific Publishing Singapore

Zhou LA (2007) Governing China's local officials: an analysis of promotion tournament model. Econ Res J 7(36):36-50. https://doi. org/10.4236/jss.2016.45008 (in Chinese)

Zhou X, Zhang J, Li J (2013) Industrial structural transformation and carbon dioxide emissions in China. Energy Policy 57:43-51. https://doi.org/10.1016/j.enpol.2012.07.017

Zhu J, Niu L, Ruth M, Shi L (2018) Technological change and energy efficiency in large Chinese firms. Ecol Econ 150:241-250. https://doi.org/10.1016/j.ecolecon.2018.04.009
Zhu X, Zuo X, Li H (2021) The dual effects of heterogeneous environmental regulation on the technological innovation of Chinese steel enterprises - based on a high-dimensional fixed effects model. Ecol Econ 188:107113. https://doi.org/10.1016/j.ecole con.2021.107113

Zhang WB, Zhang LF, Zhang KY (2010) The state and evolution of the competition in the environmental regulatory stringency on China's provincial level: a study based on two-regime spatial durbin fixed effect model. Manag World 12:34-44 (in Chinese)

Publisher's note Springer Nature remains neutral with regard to jurisdictional claims in published maps and institutional affiliations. 